\title{
Ship emissions measurement in the Arctic by plume intercepts of the Canadian Coast Guard icebreaker Amundsen from the Polar 6 aircraft platform
}

\author{
Amir A. Aliabadi ${ }^{1, \text { a }}$, Jennie L. Thomas ${ }^{2}$, Andreas B. Herber ${ }^{3}$, Ralf M. Staebler ${ }^{4}$, W. Richard Leaitch ${ }^{5}$, \\ Hannes Schulz ${ }^{3}$, Kathy S. Law ${ }^{2}$, Louis Marelle ${ }^{2,6}$, Julia Burkart ${ }^{7}$, Megan D. Willis ${ }^{7}$, Heiko Bozem ${ }^{8}$, Peter M. Hoor ${ }^{8}$, \\ Franziska Köllner ${ }^{9}$, Johannes Schneider ${ }^{9}$, Maurice Levasseur ${ }^{10}$, and Jonathan P. D. Abbatt ${ }^{7}$ \\ ${ }^{1}$ Building Technology Program, Department of Architecture, Massachusetts Institute of Technology, Cambridge, USA \\ ${ }^{2}$ LATMOS/IPSL, UPMC Univ. Paris 06 Sorbonne Universités, UVSQ, CNRS, Paris, France \\ ${ }^{3}$ Alfred Wegener Institute - Helmholtz Center for Polar and Marine Research, Bremerhaven, Germany \\ ${ }^{4}$ Processes Research Section, Air Quality Research Division, Atmospheric Science and Technology, Science and Technology \\ Branch, Environment and Climate Change Canada, Toronto, Canada \\ ${ }^{5}$ Climate Chemistry Measurements and Research Section, Climate Research Division, Atmospheric Science and Technology, \\ Science and Technology Branch, Environment and Climate Change Canada, Toronto, Canada \\ ${ }^{6}$ TOTAL S.A, Direction Scientifique, Tour Michelet, 92069 Paris, France \\ ${ }^{7}$ Department of Chemistry, University of Toronto, Toronto, Canada \\ ${ }^{8}$ Institute for Atmospheric Physics, Johannes Gutenberg University of Mainz, Mainz, Germany \\ ${ }^{9}$ Particle Chemistry Department, Max Planck Institute for Chemistry, Mainz, Germany \\ ${ }^{10}$ Département de biologie (Québec-Océan), Université Laval, Québec, Canada \\ anow at: Environmental Engineering Program, University of Guelph, Guelph, Canada
}

Correspondence to: Amir A. Aliabadi (aliabadi@aaa-scientists.com)

Received: 17 December 2015 - Published in Atmos. Chem. Phys. Discuss.: 25 January 2016

Revised: 2 June 2016 - Accepted: 9 June 2016 - Published: 29 June 2016

\begin{abstract}
Decreasing sea ice and increasing marine navigability in northern latitudes have changed Arctic ship traffic patterns in recent years and are predicted to increase annual ship traffic in the Arctic in the future. Development of effective regulations to manage environmental impacts of shipping requires an understanding of ship emissions and atmospheric processing in the Arctic environment. As part of the summer 2014 NETCARE (Network on Climate and Aerosols) campaign, the plume dispersion and gas and particle emission factors of effluents originating from the Canadian Coast Guard icebreaker Amundsen operating near Resolute Bay, NU, Canada, were investigated. The Amundsen burned distillate fuel with $1.5 \mathrm{wt} \%$ sulfur. Emissions were studied via plume intercepts using the Polar 6 aircraft measurements, an analytical plume dispersion model, and using the FLEXPART-WRF Lagrangian particle dispersion model. The first plume intercept by the research aircraft was carried
\end{abstract}

out on 19 July 2014 during the operation of the Amundsen in the open water. The second and third plume intercepts were carried out on 20 and 21 July 2014 when the Amundsen had reached the ice edge and operated under ice-breaking conditions. Typical of Arctic marine navigation, the engine load was low compared to cruising conditions for all of the plume intercepts. The measured species included mixing ratios of $\mathrm{CO}_{2}, \mathrm{NO}_{x}, \mathrm{CO}, \mathrm{SO}_{2}$, particle number concentration $(\mathrm{CN})$, refractory black carbon (rBC), and cloud condensation nuclei $(\mathrm{CCN})$. The results were compared to similar experimental studies in mid-latitudes.

Plume expansion rates $(\gamma)$ were calculated using the analytical model and found to be $\gamma=0.75 \pm 0.81,0.93 \pm 0.37$, and $1.19 \pm 0.39$ for plumes 1,2 , and 3, respectively. These rates were smaller than prior studies conducted at mid-latitudes, likely due to polar boundary layer dynamics, including reduced turbulent mixing compared to mid- 
latitudes. All emission factors were in agreement with prior observations at low engine loads in mid-latitudes. Ice-breaking increased the $\mathrm{NO}_{x}$ emission factor from $\mathrm{EF}_{\mathrm{NO}_{x}}=43.1 \pm 15.2$ to $71.6 \pm 9.68$ and $71.4 \pm 4.14 \mathrm{~g} \mathrm{~kg}-$ diesel $^{-1}$ for plumes 1, 2, and 3, likely due to changes in combustion temperatures. The $\mathrm{CO}$ emission factor was $\mathrm{EF}_{\mathrm{CO}}=137 \pm 120,12.5 \pm 3.70$ and $8.13 \pm 1.34 \mathrm{~g} \mathrm{~kg}$ diesel $^{-1}$ for plumes 1,2 , and 3. The rBC emission factor was $\mathrm{EF}_{\mathrm{rBC}}=0.202 \pm 0.052$ and $0.202 \pm 0.125 \mathrm{~g} \mathrm{~kg}$-diesel $^{-1}$ for plumes 1 and 2. The $\mathrm{CN}$ emission factor was reduced while ice-breaking from $\mathrm{EF}_{\mathrm{CN}}=2.41 \pm 0.47$ to $0.45 \pm 0.082$ and $0.507 \pm 0.037 \times 10^{16} \mathrm{~kg}$-diesel ${ }^{-1}$ for plumes 1,2 , and 3. At $0.6 \%$ supersaturation, the $\mathrm{CCN}$ emission factor was comparable to observations in mid-latitudes at low engine loads with $\mathrm{EF}_{\mathrm{CCN}}=3.03 \pm 0.933,1.39 \pm 0.319$, and $0.650 \pm 0.136 \times 10^{14} \mathrm{~kg}$-diesel $^{-1}$ for plumes 1,2 , and 3 .

\section{Introduction}

International shipping is responsible for approximately $3.3 \%$ of global $\mathrm{CO}_{2}$ emissions, 5 to $8 \%$ of global anthropogenic $\mathrm{SO}_{2}$ emissions, and $2 \%$ of global black carbon (BC) emissions (Lack and Corbett, 2012). The regulations for air pollutants released by ships are set by the International Convention for the Prevention of Pollution from Ships (MARPOL) within the International Maritime Organization (IMO) accessible at http://www.imo.org/en/OurWork/Environment/ PollutionPrevention/Pages/Default.aspx (IMO, 2015). In addition, specific sensitive regions are subject to more stringent limits for Emissions Control Areas (ECAs), such as those in effect for the Baltic Sea, the Mediterranean Sea, and the Caribbean Region. In the high Arctic, including Canadian waters, there is currently no ECA established, despite the very sensitive nature of the Arctic environment and ecosystems. At the same time, the decreasing sea ice and increasing marine navigability in the shipping season have already increased annual traffic in the Canadian Arctic in recent decades (Pizzolato et al., 2014). Future projections in Arctic ship traffic also suggest increasing emissions by mid-century (Corbett et al., 2010a; Winther et al., 2014). Development of effective regulations requires an understanding of observed ship emissions and processing in the Arctic environment.

Ship emissions measurements from land-based, marinebased, and airborne platforms have been reported in numerous studies (e.g. von Glasow et al., 2003; Chen et al., 2005; Agrawal et al., 2008; Petzold et al., 2008, 2010, 2011; Lack et al., 2009, 2011; Williams et al., 2009; Berg et al., 2012; Khan et al., 2012a; Lack and Corbett, 2012; McLaren et al., 2012; Alföldy et al., 2013; Diesch et al., 2013; Eckhardt et al., 2013; Buffaloe et al., 2014; Cappa et al., 2014; Kivekäs et al., 2014; Balzani Lööv et al., 2014; Pirjola et al., 2014; Aliabadi et al., 2015; Beecken et al., 2015; Roiger et al., 2015; Marelle et al., 2016). However, studies that attempt to measure ship emissions in the Arctic from land, marine, and airborne platforms are limited (Eckhardt et al., 2013; Aliabadi et al., 2015; Roiger et al., 2015; Marelle et al., 2016).

The sniffer method, including plume intercepts, is commonly used to study ship emission factors, where the increase in concentration or mixing ratio of pollutants compared to the background atmosphere can be observed (Berg et al., 2012; Balzani Lööv et al., 2014; Pirjola et al., 2014; Beecken et al., 2015). One prior ship plume intercept study (described in Roiger et al., 2015; Marelle et al., 2016) has been performed in the European Arctic during summer, when ships operate in the open water (no sea ice operations). Due to the particular physical and chemical properties of the Arctic boundary layer, it is important to study ships operating in sea ice and other Arctic conditions in order to compare ship emission and plume processing to observations from studies at mid-latitudes. Differences in background concentrations of reactive species in the atmosphere between high and midlatitudes, including gases and aerosols, may result in substantially different processing of ship pollutants in the Arctic. Furthermore, ship conditions when ice-breaking and conducting operations within sea ice are different, including partial engine load setting for speed reduction and ice-breaking that could affect the emission factors for pollutants significantly (e.g. Lack and Corbett, 2012).

von Glasow et al. (2003) and Petzold et al. (2008) have used a power law relationship to model ship plume dispersion as a growing semi-ellipse within the marine boundary layer. The plume growth rate has been successfully estimated for various ships in mid-latitudes and found to be in a similar range. The cold and statically stable marine boundary layer in the Arctic, which is governed by effects of surrounding ice and small changes in solar zenith angle, is likely to impact dispersion and expansion of the ship plumes differently (Anderson and Neff, 2008; Aliabadi et al., 2016a, b). This necessitates the use of the same power law model in the Arctic to compare the predicted ship plume expansion with prior studies in the mid-latitudes, with different boundary layer dynamics.

Many parameters change ship emission factors including engine load, fuel type, and emissions abatement technologies. Ship speed reduction results in better fuel economy and lower $\mathrm{CO}_{2}$ emissions, due to reduced drag on the ship hulls (Jalkanen et al., 2012; Lack and Corbett, 2012). It also reduces particulate matter, $\mathrm{BC}$, and $\mathrm{NO}_{x}$ emission factors in addition to reducing particulate matter size (Agrawal et al., 2008; Khan et al., 2012b; Petzold et al., 2010, 2011; Cappa et al., 2014). On the other hand, operating ship engines at partial load increases organic carbon (OC), BC, and CO emission factors (Agrawal et al., 2008; Petzold et al., 2011; Jalkanen et al., 2012; Khan et al., 2012b; Lack and Corbett, 2012; Cappa et al., 2014). It is desirable to compare ship emission factors in the Arctic and compare levels with observations in mid-latitudes as a function of such parameters. 
Sulfur in ship fuels is primarily converted to $\mathrm{SO}_{2}$ gas, increasing particle emissions by forming secondary sulfates (e.g. Jalkanen et al., 2012; Lack and Corbett, 2012). Lower sulfur content in ship fuels reduces particulate matter and BC emission factors (Lack et al., 2011; Petzold et al., 2011; Alföldy et al., 2013), particle size (Lack et al., 2011), and modifies the concentration of aerosols that serve as cloud condensation nuclei (CCN) (e.g. Petzold et al., 2010). It is desirable to investigate sulfur emissions of ships operating in the Arctic and verify if there is a relation between sulfur content in fuels and $\mathrm{SO}_{2}$ emissions and formation of secondary sulfates in the form of particulate matter.

Slide valves, water-in-fuel emulsion, diesel particulate filters, emulsified fuel, and sea water scrubbing are key abatement technologies to reduce emission factors for various pollutants (Corbett et al., 2010b; Lack and Corbett, 2012). While effective in reducing emission factors for certain species, these technologies cannot reduce all emission factors simultaneously. Some remedies result in reduced fuel economy (higher $\mathrm{CO}_{2}$ emissions) due to running auxiliary pumps and other equipment, while others reduce some emission factors at the expense of increasing the others (Corbett et al., 2010b; Miola et al., 2010).

\section{Research objectives}

In this study we use measurements from airborne plume intercepts to estimate emission factors for the Amundsen ship, while operating in the Arctic and burning low sulfur fuel, for gaseous and particle pollutants. In addition, we study the geometrical evolution of the Amundsen's plume in the Arctic marine boundary layer. We compare these observations to other similar studies in mid-latitudes. The first plume measurement was carried out on 19 July 2014 during the operation of the Amundsen in the Lancaster Sound of the Northwest Passage $\left(74^{\circ} 18^{\prime} \mathrm{N}, 83^{\circ} 54^{\prime} \mathrm{W}\right)$. The second and third plume measurements were carried out on 20 and 21 July 2014 after the Amundsen reached the ice edge and operated under ice conditions, north of Somerset Island, less than $50 \mathrm{~km}$ from Resolute Bay. These measurements provide differences in plume characteristics between operation under open-water conditions as well as sea ice conditions in the Arctic.

\section{Methods}

\subsection{Specifications of Amundsen icebreaker}

The Amundsen (IMO: 7510846) (Fig. 1) belongs to the Canadian Coast Guard fleet with full specifications available at http://www.ccg-gcc.gc.ca/Fleet/Vessel?vessel_id=3. It is an Arctic Class 3 vessel, $98.2 \mathrm{~m}$ long, with gross tonnage of $5911.0 \mathrm{t}$, and maximum speed of $16.0 \mathrm{kts}$. The propulsion is provided by a diesel electric AC/DC system with six main Alco M251F engines of total power $13200 \mathrm{~kW}$.

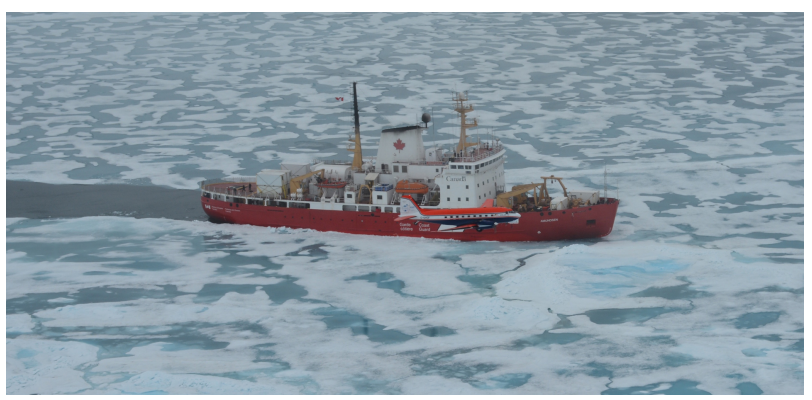

Figure 1. Snapshot of Polar 6 aircraft while sampling Amundsen's plume during ice-breaking in Lancaster Sound (Photo credit: Maurice Levasseur).

It has three Alco MLW251F generators and a Caterpillar 398 emergency generator. During the campaign, Amundsen burned marine distillate fuel that contained $1.5 \mathrm{wt} \%$ sulfur content (ISO 82172010 DMA Fuel Standard). According to the conventions for ship classifications, which are to be discussed in Sect. 3.7, the Amundsen is a medium speed diesel (MSD) ship that burns marine gas oil (MGO) with a low sulfur content.

\subsection{Airborne measurements}

The airborne instrument platform was the Polar 6 aircraft, a DC-3 converted to a Basler BT-67, owned and operated by the German Alfred Wegener Institute - Helmholtz Center for Polar and Marine Research (Fig. 1) (Leaitch et al., 2016). Below, experimental methodologies for the measurements of state parameters and meteorology, gas phase, and particle phase pollutants are presented.

\subsubsection{State parameters and meteorological measurements}

State parameters and meteorological measurements were performed by an AIMMS-20 instrument, manufactured by Aventech Research Inc., Barrie, Ontario, Canada. The instrument consisted of three modules. The Air Data Probe (ADP) measured the three-dimensional, aircraft-relative flow vector (true air speed, angle-of-attack, and sideslip). The temperature and relative humidity sensors were located in the aft section of the probe for protection. A three-axis accelerometer pack facilitated direct turbulence measurement. The inertial measurement unit (IMU) consisted of three gyros and three accelerometers providing the aircraft angular rate and acceleration. A GPS module provided the aircraft 3-D position and inertial velocity. Horizontal and vertical wind speeds were measured with accuracies of 0.50 and $0.75 \mathrm{~m} \mathrm{~s}^{-1}$, respectively. The accuracy and resolution for temperature measurement were 0.30 and $0.01{ }^{\circ} \mathrm{C}$. The accuracy and resolution for relative humidity measurement were 2.0 and $0.1 \%$. The sampling frequency was greater than $40 \mathrm{~Hz}$, but in this study a sampling frequency of $1 \mathrm{~Hz}$ was used. 


\subsubsection{Gas phase measurements}

Trace gas $\mathrm{CO}_{2}$ measurement was based on infrared absorption using an LI-7200 enclosed $\mathrm{CO}_{2} / \mathrm{H}_{2} \mathrm{O}$ Analyzer from LI-COR Biosciences $\mathrm{GmbH}$. In situ calibrations during the flight were performed on a regular time interval of 15 to 30 min using an NIST traceable calibration gas with a known $\mathrm{CO}_{2}$ concentration at atmospheric levels. Trace gas $\mathrm{CO}$ was measured with an Aerolaser ultra fast carbon monoxide (CO) monitor model AL 5002 based on VUV-fluorimetry. The same in-situ calibrations during inflight were performed. The calibrations and zero measurements allowed for corrections of instrument drifts increasing the stability and accuracy of the instrument.

During the ship emission measurements, the $\mathrm{CO}_{2}(\mathrm{CO})$ data achieved a precision $(1 \sigma, 1 \mathrm{~Hz})$ of $0.02 \mathrm{ppmv}(2.3 \mathrm{ppbv})$. The stability of the instrument was calculated to $0.62 \mathrm{ppmv}$ (4.7 ppbv), before applying the post flight data correction. Note that stability was based on the mean drift between two subsequent calibrations, which were performed during the flights. The stability was mainly affected by temperature variations. These instrumental drifts were corrected after the flights assuming a linear drift. Hence, the total uncertainty relative to the working standard of $0.62 \mathrm{ppmv}(5.23 \mathrm{ppbv})$ could be regarded as an upper limit. As can be seen in Fig. 8, the instrument precision of the $\mathrm{CO}_{2}$ and $\mathrm{CO}$ measurements allowed for identifying the ship emission plumes and further calculation of emission factors.

Trace gas $\mathrm{NO}_{x}$ measurement was based on chemiluminescence using a Thermo Scientific $42 i \mathrm{NO}-\mathrm{NO}_{2}-\mathrm{NO}_{x}$ analyzer with a time resolution of $1 \mathrm{~s}$ and an uncertainty of 0.4 ppbv. Trace gas $\mathrm{SO}_{2}$ measurement was based on UV Fluorescence light scattering using a Thermo Scientific Model 43i-TLE Enhanced Trace Level $\mathrm{SO}_{2}$ analyzer with a time resolution of $1 \mathrm{~s}$ and an uncertainty of $1 \%$ of reading or $0.2 \mathrm{ppbv}$, whichever was greater. Trace gas $\mathrm{O}_{3}$ measurement was based on UV photometry using a Thermo Scientific $49 i$ analyzer with a time resolution of $10 \mathrm{~s}$ and an uncertainty of $0.2 \mathrm{ppbv}$. For convenience trace gas mixing ratio unit of [ppbv] is presented as [ppb] hereafter.

\subsubsection{Particle phase measurements}

Particle number concentrations greater than $5 \mathrm{~nm}$ in diameter were measured with a TSI 3787 water-based ultra-fine condensation particle counter (CPC), sampling at a flow rate of $0.6 \mathrm{~L} \mathrm{~min}^{-1}$ and a time resolution of $1 \mathrm{~s}$. These measurements are referred to with subscript $\mathrm{CPC}$ or $\mathrm{CN}$ hereafter.

Aerosol particle size distributions from $70 \mathrm{~nm}$ to $1 \mu \mathrm{m}$ were measured by a Droplet Measurement Technology (DMT) ultra high sensitivity aerosol spectrometer (UHSAS) that used scattering of $1054 \mathrm{~nm}$ laser light to detect particles (Cai et al., 2008). The time resolution was $1 \mathrm{~s}$ and the measurements are referred to with subscript UHSAS hereafter.
Cloud condensation nuclei $(\mathrm{CCN})$ concentrations were measured by a DMT CCN Model 100 counter operating behind a DMT low pressure inlet at a reduced pressure of approximately $650 \mathrm{hPa}$ and a nominal water supersaturation of $1 \%$. The effective supersaturation at $650 \mathrm{hPa}$ was determined to be approximately $0.6 \%$ and was held constant throughout the study to allow for more stability of measurements, improved response, and to examine the hygroscopicity of smaller particles. The time resolution was $1 \mathrm{~s}$ and the measurements are referred to with subscript $\mathrm{CCN}$ hereafter.

Extensive calibrations and evaluations for CPC, UHSAS, and $\mathrm{CCN}$ measurements were performed in the laboratory prior to integration of the instruments on the aircraft and again with instrumentation in the aircraft at Resolute Bay. Full discussions can be found in the study by Leaitch et al. (2016).

Particle size distribution for particle diameters greater than $0.25 \mu \mathrm{m}$ was measured using a Sky optical particle counter (OPC GRIMM Model 1.129). Measurements were based on $90^{\circ}$ scattering light and a time resolution of $6 \mathrm{~s}$. The accuracy was $\pm 3 \%$ at $1 \sigma$ confidence. These measurements are referred to with subscript OPC hereafter.

The refractory black carbon ( $\mathrm{rBC}$ ) was measured using a single particle soot photometer (SP2) from DMT Boulder. The SP2 (Schwarz et al., 2010) was an instrument able to evaluate individual aerosol particles for the rBC mass content and size. The instrument used a continuous intracavity laser to classify aerosol particles as either rBC containing or purely scattering. While non-rBC particles only scattered the laser light at the same wavelength, an absorptive $\mathrm{rBC}$-containing particle passing through the laser beam was heated to its incandescence temperature and the resulting thermal radiation was measured by optical detectors as the particle vaporized. The peak incandescence signal was linearly related to the rBC mass. Size selected Fullerene soot particles were used as calibration standard. The detection efficiency of this SP2 (version D) drops off for particles smaller than $80 \mathrm{~nm}$. The time resolution was $1 \mathrm{~s}$ and the measurements are referred to with subscript SP2 hereafter.

Particle sampling is described in full detail by Leaitch et al. (2016) and was performed so that the efficiency of particle transmission to instruments would be close to $100 \%$ for particles from $20 \mathrm{~nm}$ to $1 \mu \mathrm{m}$ in diameter.

\subsubsection{Power law model for plume growth}

The methodology of von Glasow et al. (2003) describes plume dispersion with a power law, which models plume dimensions in horizontal $\left(w_{\mathrm{pl}}\right)$ and vertical $\left(h_{\mathrm{pl}}\right)$ directions.

$$
\left\{\begin{array}{l}
w_{\mathrm{pl}}(t)=w_{0}\left(\frac{t}{t_{0}}\right)^{\alpha} \\
h_{\mathrm{pl}}(t)=h_{0}\left(\frac{t}{t_{0}}\right)^{\beta}
\end{array}\right.
$$


with $w_{0}$ and $h_{0}$ being plume dimensions at reference time $\left(t_{0}=1 \mathrm{~s}\right)$ and $\alpha$ and $\beta$ being plume expansion rates in the horizontal and vertical directions. Fitted values for expansion rates are provided in the literature for mid-latitude marine boundary layers (von Glasow et al., 2003; Petzold et al., 2008); however, it remains to be verified if expansion rates are similar or different over the Arctic marine boundary layer. The power law describes plume cross-section with a semielliptic shape with area $A_{\mathrm{pl}}=\frac{\pi}{8} w_{\mathrm{pl}} h_{\mathrm{pl}}$. It is assumed that plume expansion in the vertical direction is inhibited when it reaches the top of the marine boundary layer, where subsequent expansion only continues in the horizontal direction.

A convenient and practical way to fit for plume expansion rates is to intercept a portion of the plume and measure the mixing ratio of a chemically inert species in the plume such as $\mathrm{CO}_{2}$. Assuming uniform dilution of such species in the plume, it is possible to derive a relationship between the species mixing ratio in the plume $\left(c_{\mathrm{pl}}\right)$ and expansion rate coefficients $(\alpha$ and $\beta$ ),

$\ln \left(c_{\mathrm{pl}}(t)-c_{\mathrm{bgd}}\right)=-\gamma \ln \left(\frac{t}{t_{0}}\right)+\ln \left(c_{\mathrm{pl}}\left(t_{0}\right)-c_{\mathrm{bgd}}\right)$,

where $c_{\mathrm{bgd}}$ is the background mixing ratio of the species and $\gamma$ is either $\alpha+\beta$ for plumes not reaching marine boundary layer or $\alpha$ for plumes that evolve after reaching the top of the marine boundary layer. Then $\gamma$ is the expansion rate and $m=-\gamma$ is the slope of the linear relationship. The reference time for this calculation is independent from the reference time introduced earlier. Since mixing in real plumes is not uniform, time or cross sectional averaging of the airbornemeasured mixing ratio from multiple measurements and at various distances downwind the source are necessary to arrive at a better estimate for the plume expansion rate.

\subsubsection{Estimation of plume age}

Plume age could be estimated by the aircraft measurements. For this, plume intercepts were first mapped on a latitude vs. longitude plot. This provided a scatter plot to which a plume center line was fitted with a high order polynomial. The wind measurements on board of the aircraft along the flight track and closest to each point on the center line were then used to estimate wind velocity along the plume center line. The plume age was estimated at each intercept by calculating the time it took for a parcel of air from the plume origin on the center line $(l=0)$ to travel a distance of $l=L$ along the center line and reach the nearest location to the intercept of interest using the following formula

$T(L)=\int_{l=0}^{l=L} \frac{\mathrm{d} l}{U(l)}$,

which is a line integral and $U(l)$ is the estimated horizontal wind speed along the plume center line. The plume origin on the center line was taken as the closest distance on the center line to the first intercept, and the first intercept is identified as the upstream location for wind on the latitude vs. longitude plot. (Note: since the plume growth in the power law model is self-similar, the exact position of the plume origin is arbitrary and does not affect the calculation of expansion coefficients $\alpha, \beta$ or $\alpha+\beta$.)

\subsubsection{Emission factors per kilogram of fuel burnt}

A common method to calculate emission factors (EF) in [g kg-diesel ${ }^{-1}$ ] is the net peak area method (Alföldy et al., 2013) using the $\mathrm{CO}_{2}$ mass balance concept (Hobbs et al., 2000). For a pollutant measurement in units of [ppb], the molecular weights of carbon and a gaseous pollutant species of interest are considered. Given the carbon mass percent in diesel fuel ( $87 \pm 1.5 \%$; Cooper, 2005), the emission factor for species $X$ can be expressed as

$$
\begin{aligned}
& \mathrm{EF}_{X}\left[\mathrm{~g} \mathrm{kg-diesel}^{-1}\right]=\frac{C(X)[\mathrm{ppbs}]}{C\left(\mathrm{CO}_{2}\right)[\mathrm{ppbs}]} \\
& \quad \times \frac{\mathrm{MW}_{X}\left[\mathrm{~g} \mathrm{~mol}^{-1}\right]}{\mathrm{MW}_{\mathrm{C}}=12\left[\mathrm{~g}_{\mathrm{C}} \mathrm{mol}^{-1}\right]} \times 0.87\left[\mathrm{~g}_{\mathrm{C}} \mathrm{g}_{\text {diesel }}^{-1}\right] \\
& \quad \times 1000\left[\mathrm{~g} \mathrm{~kg}^{-1}\right],
\end{aligned}
$$

where $C()$ represents the mixing ratio of species above background level integrated over time for an entire peak and MW stands for molecular weight, which for carbon is $12 \mathrm{~g} \mathrm{~mol}^{-1}$. $\mathrm{EF}$ can be estimated at a reference customary plume age or as an average for all plume encounters.

For pollutant measurement in units of mass concentration (e.g., $\left.\left[\mu \mathrm{g} \mathrm{m}^{-3}\right]\right)$, EF can be estimated using the same methodology, however, the molecular weight of the pollutant is not needed since the measurement in units of mass per volume is already available (Lack et al., 2009),

$$
\begin{aligned}
& \mathrm{EF}_{X}\left[\mathrm{~g} \mathrm{~kg} \text {-diesel }^{-1}\right]=\frac{C(X)\left[\mu \mathrm{g} \mathrm{m}^{-3} \mathrm{~s}\right]}{C\left(\mathrm{CO}_{2}\right)[\mathrm{ppbs}]} \\
& \times 1620\left[\mathrm{~g} \mathrm{\mu g}^{-1} \mathrm{~m}^{3} \mathrm{ppb} \mathrm{kg-diesel}^{-1}\right],
\end{aligned}
$$

where the constant $1620\left[\mathrm{~g} \mathrm{\mu g}^{-1} \mathrm{~m}^{3} \mathrm{ppbkg}\right.$-diesel $\left.{ }^{-1}\right]$ accounts for the same carbon mass percent in diesel fuel. For particle emissions in units of $\left[\mathrm{cm}^{-3}\right]$, the emission factor can be calculated using (Lack et al., 2009),

$$
\begin{aligned}
& \mathrm{EF}_{X}[\mathrm{~kg} \text {-diesel } \\
&
\end{aligned}
$$

where the constant $1.62 \times 10^{15}\left[\mathrm{~cm}^{3} \mathrm{ppbkg}\right.$-diesel $\left.^{-1}\right]$ accounts for the same carbon mass percent in diesel fuel.

If a modal emission factor with units of $\left[\mathrm{g} \mathrm{kWh}^{-1}\right]$ is reported, which applies to both gaseous and particle phases, it is possible to convert it to units of [ $\mathrm{g} \mathrm{kg}$-diesel $\left.{ }^{-1}\right]$ if emission 
factor for $\mathrm{CO}_{2}$ is also available in units of $\left[\mathrm{g} \mathrm{kWh}^{-1}\right]$. The conversion is provided by

$$
\begin{aligned}
& \mathrm{EF}_{X}\left[\mathrm{~g} \mathrm{~kg}_{\left.- \text {diesel }^{-1}\right]}\right]=\frac{\mathrm{EF}_{X}\left[\mathrm{~g} \mathrm{kWh}^{-1}\right]}{\mathrm{EF}_{\mathrm{CO}_{2}}\left[\mathrm{~g} \mathrm{kWh}^{-1}\right]} \\
& \times \frac{\mathrm{MW}_{\mathrm{CO}_{2}}=44\left[\mathrm{~g}_{\mathrm{CO}_{2}} \mathrm{~mol}^{-1}\right]}{\mathrm{MW}_{\mathrm{C}}=12\left[\mathrm{~g}_{\mathrm{C}} \mathrm{mol}^{-1}\right]} \times 0.87\left[\mathrm{~g}_{\mathrm{C}} \mathrm{g}_{\text {diesel }}^{-1}\right] \\
& \times 1000\left[\mathrm{~g} \mathrm{~kg}^{-1}\right] \text {. }
\end{aligned}
$$

Similarly, if a modal emission factor with units of $\left[\mathrm{kWh}^{-1}\right]$ is reported, which applies to number of particles, it is possible to convert it to units of $\left[\mathrm{kg}\right.$-diesel $\left.{ }^{-1}\right]$ if the emission factor for $\mathrm{CO}_{2}$ is also available in units of $\left[\mathrm{g} \mathrm{kWh}^{-1}\right]$. The conversion is provided by

$$
\begin{aligned}
& \mathrm{EF}_{X}\left[\mathrm{~kg}_{\text {-diesel }}^{-1}\right]=\frac{\mathrm{EF}_{X}\left[\mathrm{kWh}^{-1}\right]}{\mathrm{EF}_{\mathrm{CO}_{2}}\left[\mathrm{~g} \mathrm{kWh}^{-1}\right]} \\
& \times \frac{\mathrm{MW}_{\mathrm{CO}_{2}}=44\left[\mathrm{~g}_{\mathrm{CO}_{2}} \mathrm{~mol}^{-1}\right]}{\mathrm{MW}_{\mathrm{C}}=12\left[\mathrm{~g}_{\mathrm{C} \mathrm{mol}^{-1}}\right]} \times 0.87\left[\mathrm{~g}_{\mathrm{C}} \mathrm{g}_{\text {diesel }}^{-1}\right] \\
& \times 1000\left[\mathrm{~g} \mathrm{~kg}^{-1}\right] .
\end{aligned}
$$

The calculated EF for conserved pollutants, such as $\mathrm{CO}_{2}$, is constant and not a function of plume age. However, for other pollutants it may increase (production) or decrease (consumption) as a function of plume age. Due to a limited number of plume intercepts in this study, we computed average emission factors for all plume intercepts.

\subsection{FLEXPART-WRF plume dispersion modeling}

In order to study the dispersion of ship emissions in the Polar boundary layer, we used the FLEXPART-WRF model (Brioude et al., 2013, website: http://flexpart.eu/wiki/ FpLimitedareaWrf), a Lagrangian particle dispersion model based on FLEXPART (Stohl et al., 2005). FLEXPART-WRF was driven by meteorology from the Weather Research and Forecasting (WRF) Model (Skamarock et al., 2005), with the specifics of the WRF run for NETCARE provided in Wentworth et al. (2016). Here we ran FLEXPART-WRF in forward mode to study plume dispersion from the Amundsen. Running FLEXPART-WRF in forward mode was useful for studying the specific plume structure and emissions location for the case of a single moving point source (e.g., a single ship) involving complex movements (moving ship location with time) within a complex and changing meteorological situation. FLEXPART-WRF was run using the known ship location. Particles were released each minute along the ship track using a source extending $100 \mathrm{~m}$ vertically and horizontally centered on the ship location, from 17 July 2014 00:00 UTC to 22 July 2014 00:00 UTC. An arbitrary emissions source strength was assumed for the model run (mass of particles emitted) and considered to be constant in time for the duration of the run. FLEXPART-WRF output was saved on a grid approximately $1 \mathrm{~km} \times 1 \mathrm{~km}$ (resolution of $0.01^{\circ}$ Latitude $\times 0.05^{\circ}$ Longitude) in order to obtain results on a similar spatial scale as the plume sampling.

\subsection{Statistical analysis}

Regression was required in our analysis to relate one set of measurements to another in order to estimate the plume growth rate and various emission factors. However, since all measurements, including both dependent and independent variables, had inherent uncertainties, the ordinary least squares (OLS) approach could not be used. Instead, a multivariate least squares method, called the orthogonal distance regression (ODR), was used where the sum of squared orthogonal distances between each data point and a linear model was minimized by fitting the model coefficients (Boggs et al., 1987, 1988). A particular distribution of an ODR algorithm called ODRPACK was used that took into account the variability of both sample variables, by assuming Gaussian distributions for the uncertainties centered around zero, and fitted for the coefficients of the linear regression (Boggs et al., 1989). An error estimate for the coefficients was computed from the linearized quadratic approximation to the chi-squared $\chi^{2}$ surface at the solution with degrees of freedom $v=n-1$. In addition, a confidence band with $90 \%$ probability for the model was computed. A confidence band shows the region within which the model is expected to fall.

\section{Results and discussion}

\subsection{Meteorological context}

Plume intercepts in the 3 consecutive days are referred to as plume 1 (19 July 2014), plume 2 (20 July 2014) and plume 3 (21 July 2014). The flights were planned in advance using WRF and FLEXPART-WRF forecasts (not shown) so that the aircraft could efficiently sample ship emissions downwind of the stack. Following the campaign, WRF was run using ECMWF (European Center for Medium-Range Weather Forecasts) analysis as initial and boundary conditions, (see Table 2 of Wentworth et al., 2016), in order to refine forecast meteorology and to interpret campaign data. The quality of the meteorological data predicted by WRF has been evaluated using measurements made on-board of both the research aircraft and ship, indicating that the forecast predicted the meteorological situation during plume sampling reasonably well (wind speed and direction time series along flight tracks are shown in Fig. 2). Surface wind speed and direction predicted by WRF during plume sampling are shown in Fig. 3 . During the first plume sampling on 19 July 2014, the flight was conducted west of the ship location due to the easterly winds, characterized by high wind speeds above $10 \mathrm{~m} \mathrm{~s}^{-1}$ in Lancaster sound (Figs. 2a and 3a). For the second plume, on 20 July 2014, the ship was located just north of Somerset Island and the flight sampled ship emissions southwest of the 

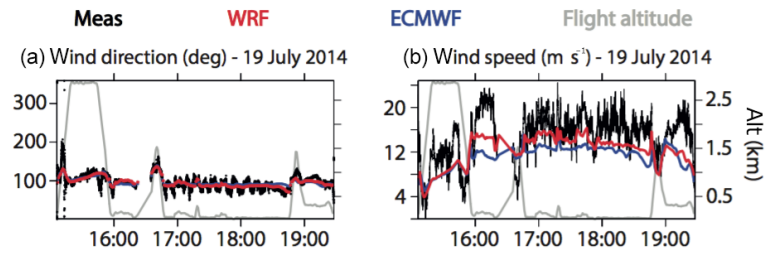

(c) Wind direction (deg) - 20 July 2014

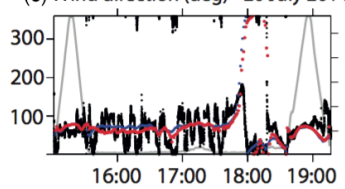

(e) Wind direction (deg) - 21 July 2014
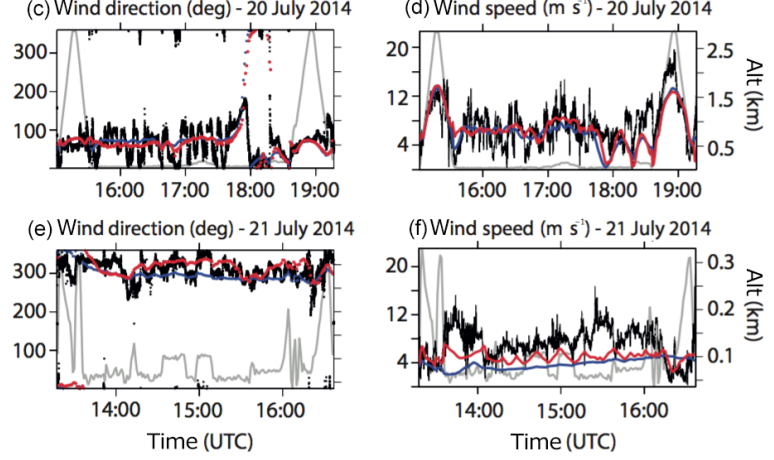

(f) Wind speed $\left(\mathrm{m} \mathrm{s}^{-1}\right)-21$ July 2014

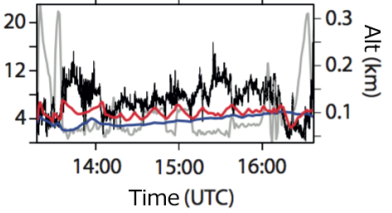

Figure 2. Measurements of wind direction and wind speed during the plume sampling flights (black). The modeled wind speed and direction interpolated in space and time to the location of the aircraft are shown for the ECMWF analysis (blue) and WRF model (red). The flight altitude is shown in grey.
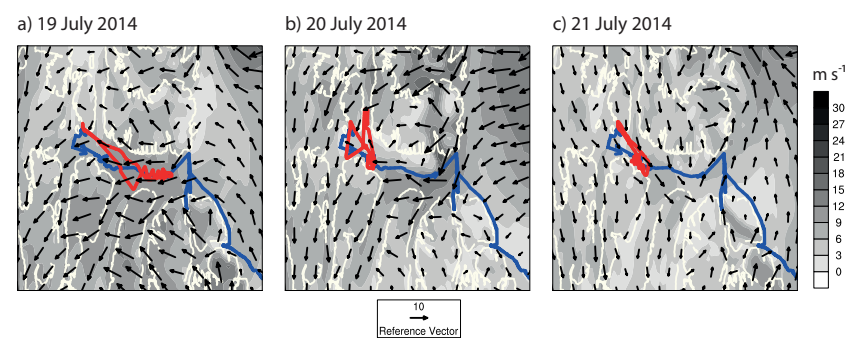

Figure 3. Snapshots of surface wind speed and direction predicted by WRF, with run details provided in Wentworth et al. (2016), during the Amundsen's ship emissions measurements by the Polar 6 aircraft for plumes 1 (a), 2 (b), and 3 (c). The shade of grey indicates surface wind speed and the arrow indicates both speed, with respect to the reference wind vector, and wind direction. The ship and aircraft tracks are indicated by red and blue traces, respectively.

ship, between the ship and the Somerset Island. The meteorological situation near the flight was less consistent in the measurement region on 20 July 2014, indicated by the variable wind directions and lower wind speeds measured. This is also shown by the variable wind speeds and directions in the region of the flight (Figs. 2b and 3b). On 21 July 2014 northwesterly winds throughout Lancaster sound resulted in plume sampling to the southeast of the ship, with consistent wind speeds (but lower than on 19 July 2014) during the plume sampling (Figs. 2c and 3c).

We also characterize boundary layer dynamics using balloon soundings launched from the ship at the times of the flights for plumes 2 and 3 (Fig. 4). For plume 1, there was no

(a) Plume 1-19 July 2014

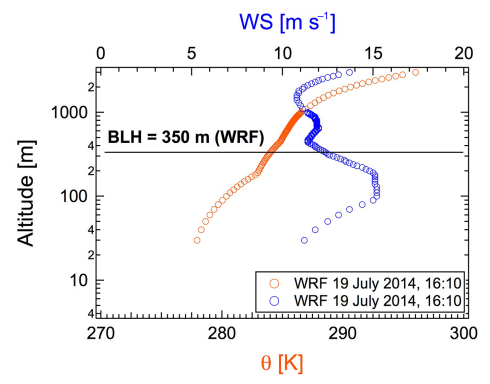

(b) Plume 2-20 July 2014

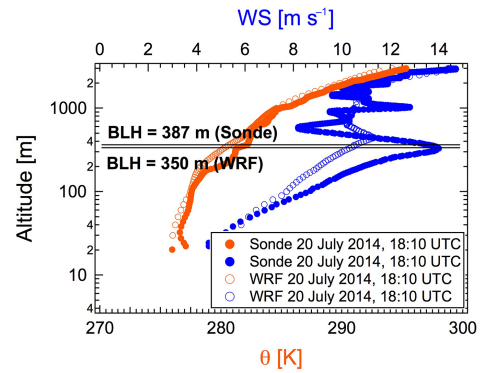

(c) Plume 3-21 July 2014

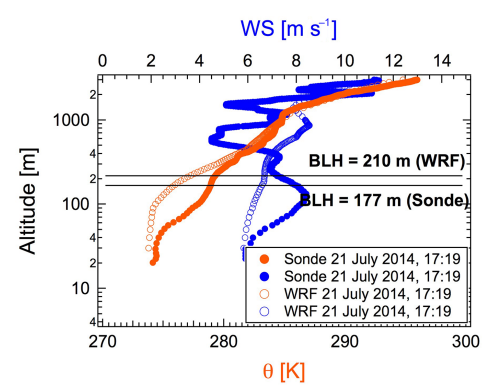

Figure 4. Vertical profiles of potential temperature $(\theta)$ and wind speed (WS) as measured with radiosondes launched from Amundsen and WRF (interpolated in space and time to the radiosonde launch location) during plumes 1 (a), 2 (b), and 3 (c). We note there was no radiosonde launched on 19 July 2014. The boundary layer height (BLH) calculated from the radiosonde and WRF data are shown with black horizontal lines.

balloon sounding, therefore we show only the WRF model results for comparison. The measurements and the model are in good agreement, noting that the model underpredicted wind speeds below $100 \mathrm{~m}$ on 21 July 2014 compared to the measurements. This is also seen in the flight track on 21 July 2014 (Fig. 2c). We also, however, note that WRF model does perform better than the ECMWF analysis (wind speed and direction) for this flight. The boundary layer is statically stable and the boundary layer height is calculated from both radiosonde measurements and the WRF model results, using the method of bulk Richardson number developed by Mahrt (1981) and later used by Aliabadi et al. (2016a). The measurements give boundary layer height as 387 and $177 \mathrm{~m}$ for plumes 2 and 3, while the model gives 


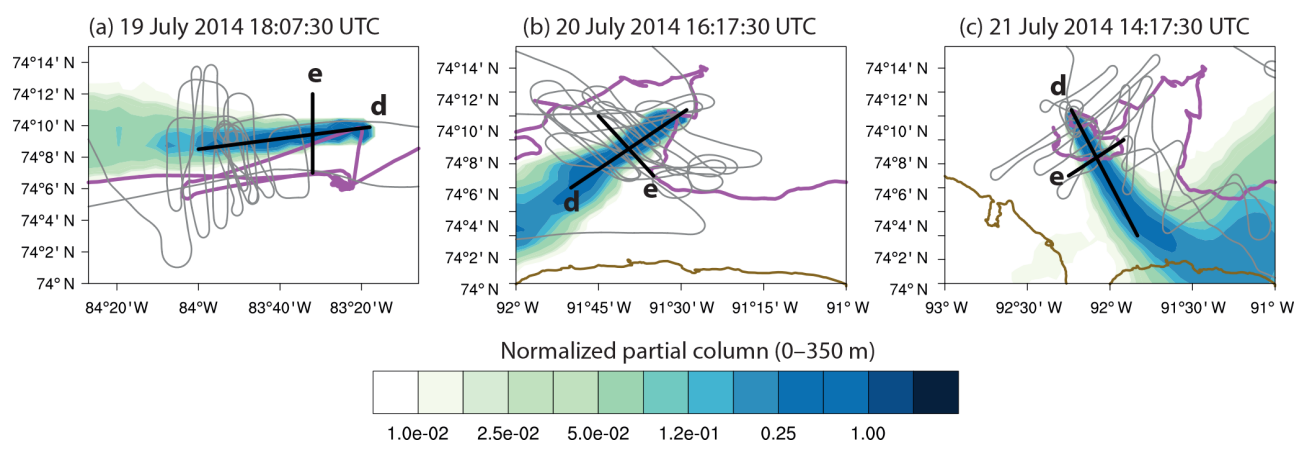

Figure 5. Snapshots of normalized FLEXPART-WRF predicted partial columns (0-350 m) indicating the location of the ship (initial location of emitted plume) and the predicted plume location. The flight track is shown in grey and the ship track is shown in magenta. The vertical plume structure is studied in Fig. 7 along the plume (noted by black line, d) and across the plume (noted by black line, e) on each panel. Coastlines are shown in gold.

(a) Plume 1-19 July 2014

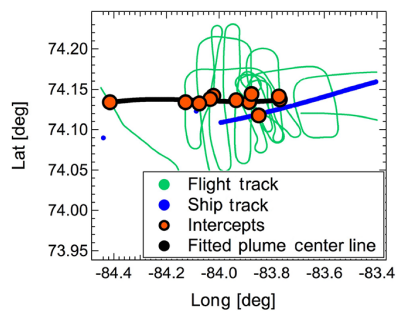

(b) Plume 2-20 July 2014

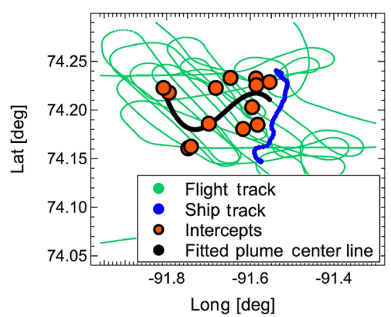

(c) Plume 3-21 July 2014

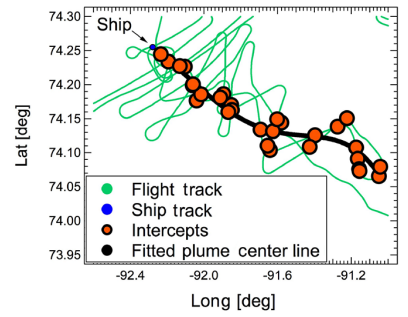

Figure 6. Plume location according to aircraft intercepts along the flight track identified as enhancements above background $\mathrm{NO}_{x}$ mixing ratio. The plume locations identified here are in agreement with normalized FLEXPART-WRF predicted partial columns in Fig. 5.

350,350 and $210 \mathrm{~m}$ for plumes 1,2 and 3, respectively. The boundary layer height estimation by the measurements and the model are reasonably close.

\subsection{Ship operating conditions}

It is known that both ship speed and engine load influence total fuel burnt and emission factors. For the Amundsen, ship speed was not directly correlated with engine load for two reasons. First, the Amundsen operated on a diesel-electric system, which could provide propulsion power using electricity while the engines were off or operating at partial load. Second, because of the specifics of ships operating in the Arctic within sea ice, even during stationary conditions, the engine could be running to power ice-breaking operations. The average ship speeds during plumes 1, 2, and 3 were $3.23 \pm 0.25,1.31 \pm 1.92$, and $0.09 \pm 0.30 \mathrm{kts}$, respectively. The variation in ship speed was calculated using 1 standard deviation, noting that both plumes 2 and 3 involved ice-breaking.

\subsection{FLEXPART-WRF ship plume modeling}

In order to show the emissions distributions in the plume on different days and the flight pattern, we used FLEXPARTWRF partial columns and vertical cross sections. Given the low boundary layer heights, maps of the plume distributions were calculated by summing the mass of particles in the lowest $350 \mathrm{~m}$ above the ocean and/or sea ice. Three example partial columns during plume sampling are shown in Fig. 5. The corresponding locations of plume crossings along the flight tracks, derived from measured peak enhancements in $\mathrm{NO}_{x}$ (see Sect. 3.4), which are used later for emission factor calculations (see Sect. 3.7), are shown in Fig. 6. The two figures indicate that the plume intercepts are in the same locations as the partial columns predicted by FLEXPART-WRF. This agreement provides confidence that the measured enhancements in trace gases and aerosols originate from the ship emissions.

The predicted vertical distribution of emissions along and across the plumes are shown in Fig. 7. The model (Fig. 7 panels marked $\mathrm{d}$ - along plume) indicated that the ship plume remained below $300 \mathrm{~m}$ when the ship was operating in the open water (plume 1) and it remained in the lowest $100 \mathrm{~m}$ when the ship was operating in sea ice (plumes 2 and 3). The vertical cross sections across the plumes (Fig. 7 panels marked e - across plume) show that the horizontal dimension of the plume covered several kilometers across. It is also worth noting that all of the plume crossings that detected ship pollutants above threshold levels occurred below $90 \mathrm{~m}$ altitude and no ship pollutants were observed above this height. 

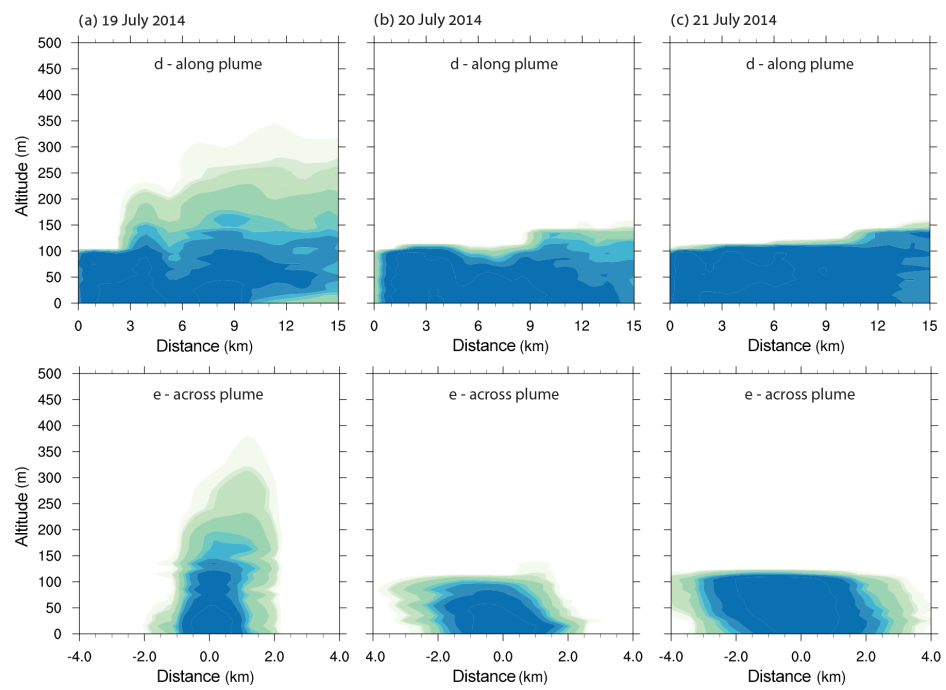

Figure 7. Vertical cross sections (normalized tracer concentrations) predicted by FLEXPART-WRF along plumes (panels marked d - along plume) and across plumes (panels marked e - across plume) for the same times as shown in Fig. 5.

This altitude range also corresponds to the most concentrated portion of the ship plume as predicted by FLEXPART-WRF (Fig. 7). The exact properties of the ship plumes were determined by the combination of the meteorological conditions, emissions injection location (horizontal and vertical extent), and the ship movements. This analysis also shows that the predicted plumes mix slowly with the background air in the strongly stable Arctic boundary layer, with implications for the fate of emissions and plume processing.

\subsection{Ship plume pollutant identification}

Plume intercepts have been identified using the methodology of Petzold et al. (2008) where a statistically significant change in mixing ratio of a non-decaying gaseous pollutant with respect to background has been observed. The average plume crossing times were $5.8 \pm 2.3 \mathrm{~s}$ (plume 1 ), $20.2 \pm 15.0 \mathrm{~s}$ (plume 2), and $38.2 \pm 52.2 \mathrm{~s}$ (plume 3). Figure 8 shows an example time series where pollution peaks in the plume are evident. This time series was used to identify the location and timing of ship plume crossings (shown in Fig. 6), which is also referred to as an excess or peak event. To identify plume crossings the $\mathrm{NO}_{x}$ mixing ratio with a threshold of $2 \mathrm{ppb}$ was used, which was preferred over $\mathrm{CO}_{2}$ due to unpredictable background variations in the $\mathrm{CO}_{2}$ mixing ratio. In this method, the background for $\mathrm{NO}_{x}$ mixing ratio was computed by averaging three consecutive measurements before and after the threshold. Once time stamps for $\mathrm{NO}_{x}$ peak events were identified, all other pollutant peaks were identified using these time stamps, without the need for a threshold. A time shift between peak events was expected between the reference instrument $\left(\mathrm{NO}_{x}\right)$ and any other instrument since they sampled air at different locations on the sampling line. This shift was identified and corrected by

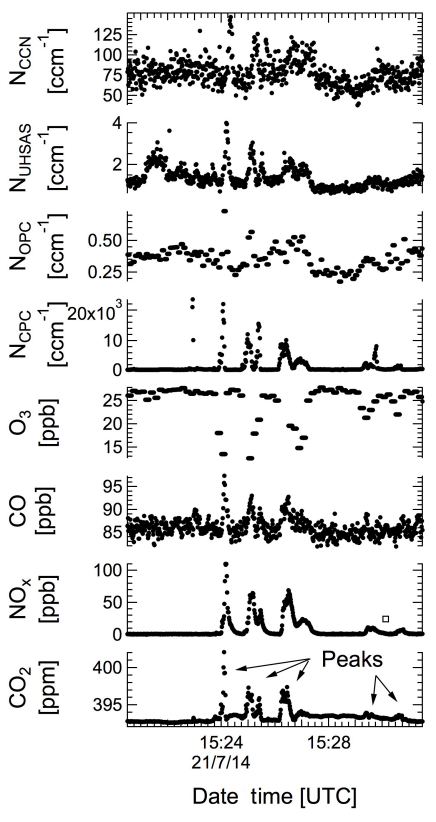

Figure 8. An example time series plot for identified pollution peaks in plume 3; sampling time for all instruments is $1 \mathrm{~s}$ except for $\mathrm{O}_{3}$ $(10 \mathrm{~s})$ and OPC (5s).

maximizing the coefficient of determination $\left(R^{2}\right)$ for the 1-1 mixing ratio plots between a pair of instruments.

\subsection{Analytical model of ship plume expansion}

Using airborne meteorological and $\mathrm{CO}_{2}$ mixing ratio measurements, the power law plume expansion model (Eqs. 1 and 2), and the estimated plume age (Eq. 3), the plume geometrical evolution could be explained for all of the plumes. 
(a) Plume 1-19 July 2014

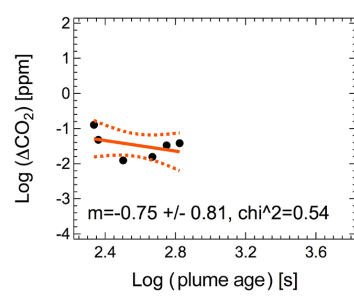

(b) Plume 2-20 July 2014

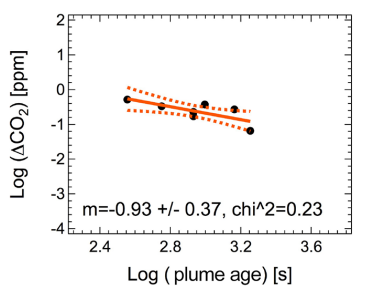

(c) Plume 3-21 July 2014

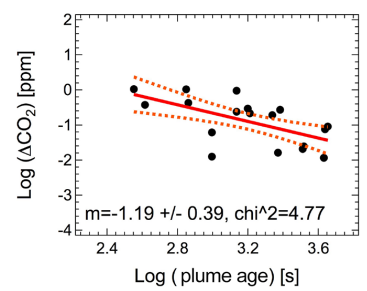

Figure 9. Calculated plume growth or expansion rate $(\gamma=-m)$ along the flight tracks using aircraft measurements for plumes 1 (a), 2 (b), and 3 (b). Note: using the methodology in Sect. 2.2 .5 a plume age could be assigned to $n=6$ data points for plume $1, n=7$ data points for plume 2 , and $n=18$ data points for plume 3 .

In this calculation, the vertical variations in wind speed and direction were accounted for. Using the methodology in Sect. 2.2.5 a plume age could be assigned to $n=6$ data points for plume $1, n=7$ data points for plume 2 , and $n=18$ data points for plume 3. Figure 9 shows the measured expansion rates for these data points. The expansion rate is the magnitude of slope for the fitted lines $(\gamma=\alpha+\beta$ for our case where dispersion occurred within the boundary layer and the plumes did not reach the top of the boundary layer), and it was calculated as $\gamma=0.75 \pm 0.81,0.93 \pm 0.37$, and $1.19 \pm 0.39$ for plumes 1,2 and 3 , respectively. The uncertainties in the expansion rates resulted not only from uncertainties in plume age estimation or $\mathrm{CO}_{2}$ measurements, but also from the intermittent mixing of air parcels under stable conditions (Aliabadi et al., 2016b), which caused nonuniform dilution of $\mathrm{CO}_{2}$ and therefore a scatter in mixing ratios. These expansion rates compare reasonably well but are lower than those values reported in the literature for mid-latitudes. Petzold et al. (2008) find $\gamma=1.5 \pm 0.06$ for a ship plume expansion in the English Channel, and von Glasow et al. (2003) find a best guess value of $\gamma=1.35$ for a number of previous studies also in mid-latitudes. Our lower expansion rate suggests that ship plumes in the Arctic marine boundary layer mix with the background to a lesser extent compared to mid-latitude due to the statically stable conditions. An examination of Figs. 2 and 7 suggests that when wind speeds were low (Figs. 2b, c and 7b, c) there was a significant suppression of vertical mixing in comparison to horizontal mixing, i.e., $\alpha \gg \beta$, within the stable boundary layer, but when wind speeds were high (Figs. 2a and 7a) vertical mixing was enhanced, i.e., $\alpha \sim \beta$, but the stable boundary layer still resulted in lower overall mixing and expansion rate compared to mid-latitude observations.

\subsection{Changes in gas mixing ratios and particle concentrations}

\subsubsection{Gas Pollutants}

Figure 10 shows the scatter plot for excess gas pollutants vs. excess carbon dioxide using the net peak area method. In all (a) Plume 1-19 July 2014

(b) Plume 2-20 July 2014

(c) Plume 3-21 July 2014
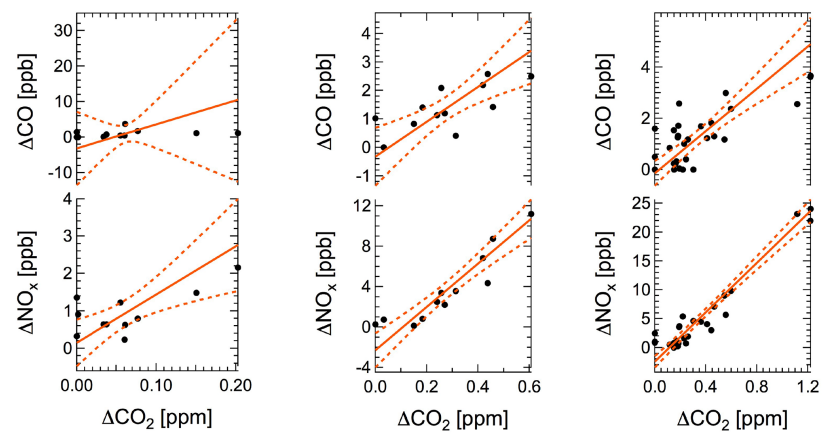

Figure 10. Scatter plot for excess gas pollutant mixing ratio vs. excess $\mathrm{CO}_{2}$ for plumes 1 (a), 2 (b), and 3 (c). Measurements are shown by black markers. The linear model fit is shown with solid red line, and the $90 \%$ confidence band for the linear model fit is shown with dashed red lines.

three instances, excess carbon monoxide and nitrogen dioxide correlated with excess carbon dioxide. Given the lower detection limit of the instrument, there was no trace of $\mathrm{SO}_{2}$ in the plume as measured by the aircraft. It has been verified by $\mathrm{SO}_{2}$ measurements on-board of the ship that the mixing ratios were below $2 \mathrm{ppb}$, indicating that the exhaust after treatment on the Amundsen effectively removed this species (J. J. Wentzell, personal communication, 2015).

Table 1 shows the results for ODR analysis for excess gas pollutants vs. excess carbon dioxide. The Pearson's chisquared test for goodness of fit indicated that with the degrees of freedom $v=10,11$, and 28 , the probability of observing the computed values of $\chi^{2}$ is $P>0.975$, significantly greater than conventional criteria for statistical significance (0.001-0.005). The regression slope $(b)$ for excess oxides of nitrogen in plume 1 was a factor of 2-3 less than plumes 2 and 3 , attributed to ice-breaking conditions, and hence higher engine temperature (but not necessarily engine load), during plumes 2 and 3 . The uncertainty for fit coefficient $b$ for carbon monoxide in plume 1 was significant, so we could not make a statement to relate this value to observations in plumes 2 and 3 . 
Table 1. Linear regression analysis for excess gas pollutant mixing ratio vs. excess carbon dioxide; $[\Delta X]=a+b\left[\Delta \mathrm{CO}_{2}\right]$, where $X$ is any gas pollutant species; the uncertainty is computed using the orthogonal distance regression (ODR) method.

\begin{tabular}{|c|c|c|c|c|}
\hline Species & $v=n-1$ & $\chi^{2}$ & $a$ [ppb] & $b\left[\mathrm{ppb} \mathrm{ppm}^{-1}\right]$ \\
\hline \multicolumn{5}{|c|}{ Plume 1} \\
\hline $\begin{array}{l}\Delta \mathrm{NO}_{x} \\
\Delta \mathrm{CO}\end{array}$ & $\begin{array}{l}10 \\
10\end{array}$ & $\begin{array}{l}2.15 \times 10^{-2} \\
3.82 \times 10^{-2}\end{array}$ & $\begin{array}{r}1.44 \times 10^{-1} \pm 3.41 \times 10^{-1} \\
-3.23 \pm 5.64\end{array}$ & $\begin{array}{r}1.29 \times 10^{1} \pm 4.56 \\
6.76 \times 10^{1} \pm 8.87 \times 10^{1}\end{array}$ \\
\hline \multicolumn{5}{|c|}{ Plume 2} \\
\hline $\begin{array}{l}\Delta \mathrm{NO}_{x} \\
\Delta \mathrm{CO}\end{array}$ & $\begin{array}{l}11 \\
11\end{array}$ & $\begin{array}{l}5.43 \times 10^{-2} \\
1.65 \times 10^{-1}\end{array}$ & $\begin{array}{r}-2.30 \pm 9.34 \times 10^{-1} \\
-3.30 \times 10^{-1} \pm 5.61 \times 10^{-1} \\
\end{array}$ & $\begin{array}{r}2.15 \times 10^{1} \pm 2.9 \\
6.14 \pm 1.82\end{array}$ \\
\hline \multicolumn{5}{|c|}{ Plume 3} \\
\hline $\begin{array}{l}\Delta \mathrm{NO}_{x} \\
\Delta \mathrm{CO}\end{array}$ & $\begin{array}{l}28 \\
28\end{array}$ & $\begin{array}{r}2.56 \times 10^{-1} \\
1.25\end{array}$ & $\begin{array}{r}-2.46 \pm 5.77 \times 10^{-1} \\
-1.42 \times 10^{-1} \pm 2.85 \times 10^{-1}\end{array}$ & $\begin{array}{r}2.14 \times 10^{1} \pm 1.24 \\
4.13 \pm 6.64 \times 10^{-1}\end{array}$ \\
\hline
\end{tabular}

Table 2. Linear regression analysis for excess particle concentration vs. excess carbon dioxide; $[\Delta X]=a+b\left[\Delta \mathrm{CO}_{2}\right]$, where $X$ is any particle concentration; the uncertainty is computed using the orthogonal distance regression (ODR) method.

\begin{tabular}{|c|c|c|c|c|}
\hline Species & $v=n-1$ & $\chi^{2}$ & $a\left[\mathrm{ccm}^{-1}\right]$ or $\left[\mu \mathrm{g} \mathrm{m}^{-3}\right]$ & $b\left[\mathrm{ccm}^{-1} \mathrm{ppm}^{-1}\right]$ or $\left[\mu \mathrm{g} \mathrm{m}^{-3} \mathrm{ppm}^{-1}\right]$ \\
\hline \multicolumn{5}{|c|}{ Plume 1} \\
\hline$\Delta \mathrm{N}_{\mathrm{CPC}}\left[\mathrm{ccm}^{-1}\right]$ & 10 & $2.06 \times 10^{-2}$ & $5.22 \times 10^{1} \pm 2.77 \times 10^{2}$ & $1.49 \times 10^{4} \pm 2.92 \times 10^{3}$ \\
\hline$\Delta \mathrm{N}_{\mathrm{OPC}}\left[\mathrm{ccm}^{-1}\right]$ & 10 & $1.66 \times 10^{-2}$ & $-2.68 \times 10^{-2} \pm 3.35 \times 10^{-2}$ & $1.34 \pm 4.14 \times 10^{-1}$ \\
\hline$\Delta \mathrm{N}_{\text {UHSAS }}\left[\mathrm{ccm}^{-1}\right]$ & 10 & $2.46 \times 10^{-2}$ & $-5.57 \times 10^{-2} \pm 2.4 \times 10^{-1}$ & $7.99 \pm 3.29$ \\
\hline$\Delta \mathrm{rBC}_{\mathrm{SP} 2}\left[\mu \mathrm{g} \mathrm{m}^{-3}\right]$ & 10 & $3.74 \times 10^{-4}$ & $3.27 \times 10^{-3} \pm 2.79 \times 10^{-3}$ & $1.25 \times 10^{-1} \pm 3.22 \times 10^{-2}$ \\
\hline$\Delta \mathrm{N}_{\mathrm{CCN}}\left[\mathrm{ccm}^{-1}\right]$ & 10 & $1.87 \times 10^{-2}$ & $-7.47 \times 10^{-1} \pm 4.39$ & $1.87 \times 10^{2} \pm 5.76 \times 10^{1}$ \\
\hline \multicolumn{5}{|c|}{ Plume 2} \\
\hline$\Delta \mathrm{N}_{\mathrm{CPC}}\left[\mathrm{ccm}^{-1}\right]$ & 11 & $1.55 \times 10^{-1}$ & $2.62 \times 10^{2} \pm 1.67 \times 10^{2}$ & $2.78 \times 10^{3} \pm 5.07 \times 10^{2}$ \\
\hline$\Delta \mathrm{N}_{\mathrm{OPC}}\left[\mathrm{ccm}^{-1}\right]$ & 11 & $2.48 \times 10^{-2}$ & $3.06 \times 10^{-2} \pm 2.81 \times 10^{-2}$ & $1.85 \times 10^{-1} \pm 8.55 \times 10^{-2}$ \\
\hline$\Delta N_{\text {UHSAS }}\left[\mathrm{ccm}^{-1}\right]$ & 11 & $2.29 \times 10^{-1}$ & $-6.68 \times 10^{-1} \pm 5.01 \times 10^{-1}$ & $3.95 \pm 1.67$ \\
\hline$\Delta \mathrm{rBC}_{\mathrm{SP} 2}\left[\mu \mathrm{g} \mathrm{m}^{-3}\right]$ & 11 & $2.05 \times 10^{-2}$ & $9.17 \times 10^{-3} \pm 2.53 \times 10^{-2}$ & $1.25 \times 10^{-1} \pm 7.69 \times 10^{-2}$ \\
\hline$\Delta \mathrm{N}_{\mathrm{CCN}}\left[\mathrm{ccm}^{-1}\right]$ & 11 & $1.21 \times 10^{-1}$ & $-3.77 \pm 6.17$ & $8.60 \times 10^{1} \pm 1.97 \times 10^{1}$ \\
\hline \multicolumn{5}{|c|}{ Plume 3} \\
\hline$\Delta \mathrm{N}_{\mathrm{CPC}}\left[\mathrm{ccm}^{-1}\right]$ & 28 & $4.50 \times 10^{-1}$ & $2.93 \times 10^{2} \pm 1.06 \times 10^{2}$ & $3.13 \times 10^{3} \pm 2.30 \times 10^{2}$ \\
\hline$\Delta \mathrm{N}_{\mathrm{OPC}}\left[\mathrm{ccm}^{-1}\right]$ & 28 & $2.68 \times 10^{-2}$ & $3.25 \times 10^{-2} \pm 8.55 \times 10^{-3}$ & $6.11 \times 10^{-2} \pm 1.80 \times 10^{-2}$ \\
\hline$\Delta \mathrm{N}_{\text {UHSAS }}\left[\mathrm{ccm}^{-1}\right]$ & 28 & $1.96 \times 10^{-1}$ & $4.03 \times 10^{-2} \pm 2.60 \times 10^{-2}$ & $5.13 \times 10^{-1} \pm 5.49 \times 10^{-2}$ \\
\hline$\Delta \mathrm{N}_{\mathrm{CCN}}\left[\mathrm{ccm}^{-1}\right]$ & 28 & 1.67 & $-2.23 \times 10^{-1} \pm 3.45$ & $4.01 \times 10^{1} \pm 8.42$ \\
\hline
\end{tabular}

\subsubsection{Particle pollutants}

Figure 11 shows the scatter plot for excess particle concentrations vs. excess carbon dioxide using the net peak area method. A correlation was noticeable for all instruments. The SP2 instrument was not functional during plume 3. Table 2 shows the results for the ODR analysis for excess particle concentrations vs. excess carbon dioxide. The regression slope $(b)$ for plume 1 associated with CPC, OPC, UHSAS, and CCN concentrations were factors of 5, 4-10, 2-3, 2-5 higher than plumes 2 and 3 . This could be related to possi- ble higher engine load (also vessel speed), but lower engine temperature according to Sect. 3.6.1, for this plume.

\subsection{Emission factors}

Emission factors (EF) in the literature are reported in different ways. Some studies report EF for one ship or a fleet of ships operating under typical engine loading conditions or fuel types (HFO: heavy fuel oil with high sulfur content, and MGO: marine gas oil with low sulfur content) (Petzold et al., 2008; Lack et al., 2011; Khan et al., 2012a; Alföldy et al., 2013). Another common approach is to group EF based on 
Table 3. Emission factors for $\mathrm{NO}_{x}$; numbers in brackets indicate engine load (\%), fuel type (HFO: heavy fuel oil with high sulfur content, and MGO: marine gas oil with low sulfur content), or vessel class based on gross metric tonnage (HSD: high speed diesel < 5000 t, MSD: medium speed diesel 5000-30000 t, or SSD: slow speed diesel > 50000t); the uncertainty is computed using the orthogonal distance regression (ODR) method.

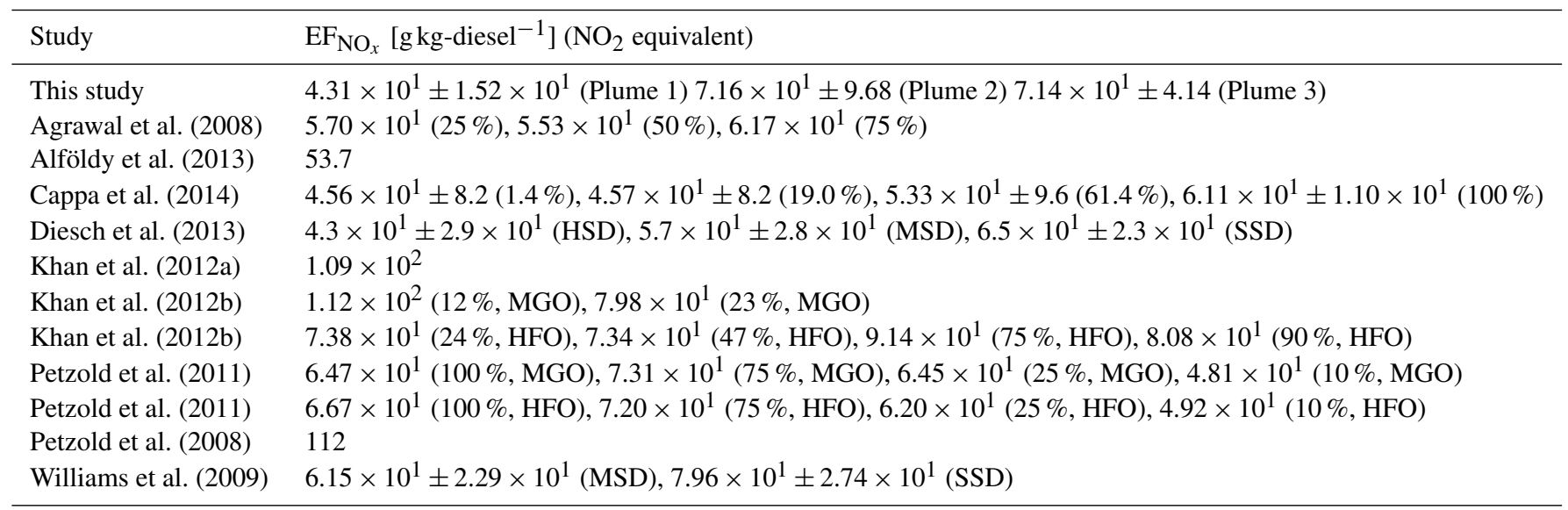

(a) Plume 1-19 July 2014

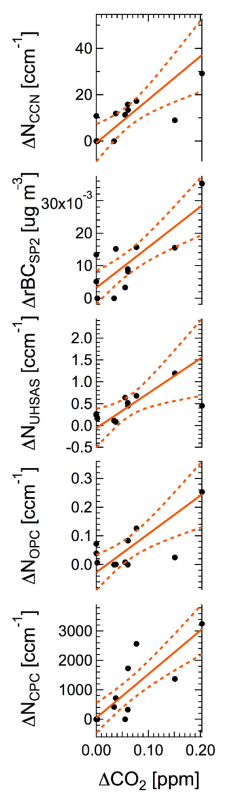

(b) Plume 2-20 July 2014

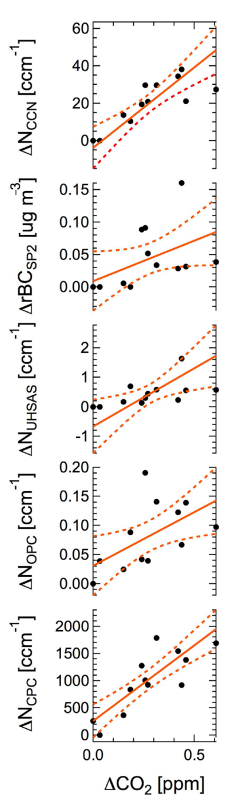

(c) Plume 3-21 July 2014
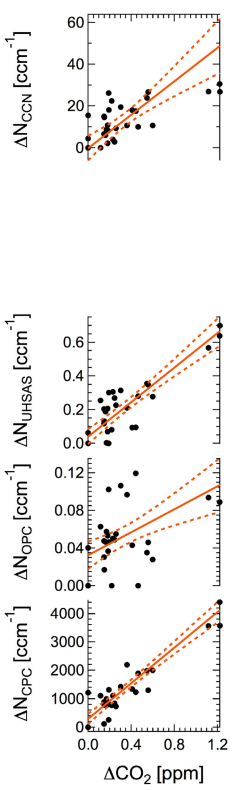

Figure 11. Scatter plot for excess particle concentration vs. excess carbon dioxide for plumes 1 (a), 2 (b), and 3 (c). Measurements are shown by black markers. The linear model fit is shown with a solid red line, and the $90 \%$ confidence band for the linear model fit is shown with dashed red lines.

vessel gross tonnage in HSD: high speed diesel $<5000 \mathrm{t}$, MSD: medium speed diesel 5000-30000t, or SSD: slow speed diesel > $50000 \mathrm{t}$ categories (Lack et al., 2008, 2009; Williams et al., 2009; Diesch et al., 2013; Buffaloe et al., 2014). The other approach is to report EF for a single ship operating on specific fuel type as a function of engine load

(Agrawal et al., 2008; Petzold et al., 2010, 2011; Khan et al., 2012b; Cappa et al., 2014).

\subsubsection{Gas pollutants}

Figure 12 and Table 3 show emission factors for $\mathrm{NO}_{x}$ in this study in comparison to other studies in the literature. $\mathrm{EF}_{\mathrm{NO}_{x}}$ was expected to increase for engines operating at higher temperatures (thermal $\mathrm{NO}_{x}$ ) (Sinha et al., 2003; Diesch et al., 2013; Cappa et al., 2014). Higher engine loads have been shown to increase $\mathrm{EF}_{\mathrm{NO}_{x}}$ (Agrawal et al., 2008; Petzold et al., 2011; Khan et al., 2012b; Cappa et al., 2014). Increasing gross tonnage has also been shown to result in higher $\mathrm{EF}_{\mathrm{NO}_{x}}$ (Williams et al., 2009; Diesch et al., 2013). $\mathrm{EF}_{\mathrm{NO}_{x}}$ in this study was in good agreement with other studies particularly for low engine loads and HSD-MSD vessel categories. However there was an increase in $\mathrm{EF}_{\mathrm{NO}}$ by a factor of 2-3 for plumes 2 and 3 compared to plume 1 . This suggests that icebreaking during these two plumes resulted in higher engine temperatures that correspondingly increased $\mathrm{EF}_{\mathrm{NO}_{x}}$.

Figure 13 and Table 4 show emission factors for $\mathrm{CO}$ in this study in comparison to other studies in the literature. Emission factors for carbon monoxide $\left(\mathrm{EF}_{\mathrm{CO}}\right)$ are expected to drop with increasing ship engine load (speed) (Agrawal et al., 2008, 2010; Moldanová et al., 2009; Petzold et al., 2011; Jalkanen et al., 2012; Khan et al., 2012b; Cappa et al., 2014). $\mathrm{EF}_{\mathrm{CO}}$ in this study was in good agreement with other studies for which the vessel speed was very slow. (Note: the emission factor is not shown for plume 1 due to the very high uncertainty.)

\subsubsection{Particle pollutants}

Figure 14 and Table 5 show emission factors for $\mathrm{rBC}$ in this study in comparison to other studies in the literature. It is im- 
Table 4. Emission factors for CO; numbers in brackets indicate engine load (\%), fuel type (HFO: heavy fuel oil with high sulfur content, and MGO: marine gas oil with low sulfur content), or vessel class based on gross metric tonnage (HSD: high speed diesel < 5000 t, MSD: medium speed diesel 5000-30000 t, or SSD: slow speed diesel $>50000 \mathrm{t}$ ); the uncertainty is computed using the orthogonal distance regression $(\mathrm{ODR})$ method.

\begin{tabular}{ll}
\hline Study & $\mathrm{EF}_{\mathrm{CO}}\left[\mathrm{g} \mathrm{kg-diesel}{ }^{-1}\right]$ \\
\hline This study & $1.37 \times 10^{2} \pm 1.80 \times 10^{2}\left(\right.$ Plume 1) $1.25 \times 10^{1} \pm 3.70$ (Plume 2) $8.13 \pm 1.34$ (Plume 3) \\
Agrawal et al. (2008) & $4.6(25 \%), 3.2(50 \%), 2.1(75 \%)$ \\
Cappa et al. (2014) & $6.23 \pm 1.2(1.4 \%), 5.83 \pm 9 \times 10^{-1}(19.0 \%), 2.92 \pm 5.8 \times 10^{-1}(61.4 \%), 2.50 \pm 5.0 \times 10^{-1}(100 \%)$ \\
Khan et al. (2012a) & 6.38 \\
Khan et al. (2012b) & $1.7(12 \%, \mathrm{MGO}), 9.0(23 \%, \mathrm{MGO})$ \\
Khan et al. (2012b) & $8.4(24 \%, \mathrm{HFO}), 6.11(47 \%, \mathrm{HFO}), 1.7(75 \%, \mathrm{HFO}), 1.9(90 \%, \mathrm{HFO})$ \\
Petzold et al. (2011) & $8.6 \times 10^{-1}(100 \%, \mathrm{MGO}), 8.5 \times 10^{-1}(75 \%, \mathrm{MGO}), 2.39(25 \%, \mathrm{MGO}), 5.49(10 \%, \mathrm{MGO})$ \\
Petzold et al. (2011) & $9.5 \times 10^{-1}(100 \%, \mathrm{HFO}), 8.9 \times 10^{-1}(75 \%, \mathrm{HFO}), 2.49(25 \%, \mathrm{HFO}), 4.47(10 \%, \mathrm{HFO})$ \\
Williams et al. (2009) & $1.1 \times 10^{1} \pm 1.42 \times 10^{1}(\mathrm{MSD}), 1.18 \times 10^{1} \pm 1.17 \times 10^{1}(\mathrm{SSD})$ \\
\hline
\end{tabular}

Table 5. Emission factors for black carbon; numbers in brackets indicate engine load (\%), fuel type (HFO: heavy fuel oil with high sulfur content, and MGO: marine gas oil with low sulfur content), or vessel class based on gross metric tonnage (HSD: high speed diesel $<5000 \mathrm{t}$, MSD: medium speed diesel 5000-30000 t, or SSD: slow speed diesel $>50000 \mathrm{t}$ ); ${ }^{\mathrm{a}}$ elemental carbon, filter measurement based on a thermal/optical carbon aerosol analyzer according to NIOSH 5040; b black carbon measurement based on weighted average using SP2, SP-AMS, PAS, and PSAP; ${ }^{c}$ black carbon measurement based on weighted average using SP2, SP-AMS, PAS-G, PAS-B, and PSAP; ${ }^{d}$ black carbon measurement based on multiple angle absorption photometer (MAAP); ${ }^{e}$ light absorbing carbon measurement based on photo-acoustic techniques; ${ }^{\mathrm{f}}$ black carbon measurement based on PAS; $\mathrm{g}$ elemental carbon, filter measurement based on a multi-step combustion method according to VDI guideline 2465-2; the uncertainty is computed using the orthogonal distance regression (ODR) method.

\begin{tabular}{|c|c|}
\hline Study & $\mathrm{EF}_{\mathrm{rBC}}\left[\mathrm{g} \mathrm{kg}_{\text {-diesel }}{ }^{-1}\right]$ \\
\hline This study & $2.02 \times 10^{-1} \pm 5.22 \times 10^{-2}$ (Plume 1) $2.02 \times 10^{-1} \pm 1.25 \times 10^{-1}$ (Plume 2$)$ \\
\hline Agrawal et al. $(2008)^{\mathrm{a}}$ & $6.8 \times 10^{-2}(25 \%), 3.4 \times 10^{-2}(50 \%), 2.1 \times 10^{-2}(75 \%)$ \\
\hline Buffaloe et al. $(2014)^{\mathrm{b}}$ & $3.2 \times 10^{-1} \pm 2.6 \times 10^{-1}(\mathrm{HSD}), 2.7 \times 10^{-1} \pm 1.2 \times 10^{-1}(\mathrm{MSD}), 2.1 \times 10^{-1} \pm 1.6 \times 10^{-1}(\mathrm{SSD})$ \\
\hline Cappa et al. $(2014)^{\mathrm{c}}$ & $4.0 \times 10^{-2}(1.4 \%), 1.5 \times 10^{-1}(19.0 \%), 4.1 \times 10^{-1}(61.4 \%), 4.1 \times 10^{-1}(100 \%)$ \\
\hline Diesch et al. $(2013)^{\mathrm{d}}$ & $2.1 \times 10^{-1} \pm 2.3 \times 10^{-1}(\mathrm{HSD}), 1.4 \times 10^{-1} \pm 1.6 \times 10^{-1}(\mathrm{MSD}), 1.2 \times 10^{-1} \pm 8.0 \times 10^{-2}(\mathrm{SSD})$ \\
\hline Khan et al. $(2012 b)^{a}$ & $1.0 \times 10^{-2}(12 \%, \mathrm{MGO}), 1.6 \times 10^{-2}(23 \%, \mathrm{MGO})$ \\
\hline Khan et al. $(2012 b)^{a}$ & $4.3 \times 10^{-2}(24 \%, \mathrm{HFO}), 2.9 \times 10^{-2}(47 \%, \mathrm{HFO}), 2.3 \times 10^{-2}(75 \%, \mathrm{HFO}), 2.1 \times 10^{-2}(90 \%, \mathrm{HFO})$ \\
\hline Lack et al. (2009) $)^{\mathrm{e}}$ & $1.0 \pm 7.0 \times 10^{-1}(\mathrm{MSD}), 7.0 \times 10^{-1} \pm 8.0 \times 10^{-1}(\mathrm{SSD})$ \\
\hline Lack et al. $(2011)^{\mathrm{f}}$ & $2.2 \times 10^{-1} \pm 9.0 \times 10^{-2}(\mathrm{MGO}), 1.3 \times 10^{-1} \pm 5.0 \times 10^{-2}(\mathrm{HFO})$ \\
\hline Lack et al. $(2008)^{\mathrm{e}}$ & $3.6 \times 10^{-1} \pm 2.3 \times 10^{-1}(\mathrm{HSD}), 9.7 \times 10^{-1} \pm 6.6 \times 10^{-1}(\mathrm{MSD}), 4.1 \times 10^{-1} \pm 2.7 \times 10^{-1}(\mathrm{SSD})$ \\
\hline Petzold et al. $(2011)^{\mathrm{d}}$ & $5.0 \times 10^{-3}(100 \%, \mathrm{MGO}), 6.0 \times 10^{-3}(75 \%, \mathrm{MGO}), 1.6(25 \%, \mathrm{MGO}), 7.0 \times 10^{-3}(10 \%, \mathrm{MGO})$ \\
\hline Petzold et al. (2011) $)^{\mathrm{d}}$ & $9.9 \times 10^{-2}(100 \%, \mathrm{HFO}), 6.1 \times 10^{-2}(75 \%, \mathrm{HFO}), 5.3 \times 10^{-2}(25 \%, \mathrm{HFO}), 1.78 \times 10^{-1}(10 \%, \mathrm{HFO})$ \\
\hline Petzold et al. (2010) ${ }^{\mathrm{d}}$ & $7.5 \times 10^{-2}(100 \%), 5.7 \times 10^{-2}(85 \%), 7.2 \times 10^{-2}(50 \%), 2.04 \times 10^{-1}(25 \%), 3.67 \times 10^{-1}(10 \%)$ \\
\hline Petzold et al. (2008) & $0.179 \pm 0.018$ \\
\hline
\end{tabular}

portant to realize that estimates for BC measurements significantly depend on the methodology used, so caution should be used in interpreting data. For example, refractory derived SP2 measurements of BC underestimate BC emissions by a factor of about 2 relative to other techniques, likely due to methodological limitations, such as the limited range for particle detection $\left(60 \mathrm{~nm}<d_{\mathrm{p}, \mathrm{VED}}<300 \mathrm{~nm}\right)$ (Buffaloe et al., 2014; Cappa et al., 2014), and so where possible, combining multiple measurement techniques for $\mathrm{BC}$ is desirable. With this consideration, our estimated $\mathrm{EF}_{\mathrm{rBC}}$ was in good agreement with other studies with low engine loading (Petzold et al., 2010, 2011). The effect of engine load on $\mathrm{EF}_{\mathrm{rBC}}$ has been debated in the literature. While Agrawal et al. (2008);
Petzold et al. (2010, 2011); Khan et al. (2012b) find increasing emission factors by decreasing engine loading, Cappa et al. (2014) find the opposite trend.

Figure 15 and Table 6 show emission factors for total particle count in this study in comparison to other studies in the literature. The caveat in this comparison was the difference in lower size limit for CPC measurements. For this purpose, we have provided lower size limits for other studies. Regardless, $\mathrm{EF}_{\mathrm{CN}}$ for plume 1 was higher by a factor of 5 compared to plumes 2 and 3 . This suggests that higher engine loading resulted in higher $\mathrm{EF}_{\mathrm{CN}}$. This is in agreement with studies by Petzold et al. (2010) and Cappa et al. (2014) although the 
Table 6. Emission factors for total particle count $\times 10^{16}$; numbers in brackets indicate engine load (\%), fuel type (HFO: heavy fuel oil with high sulfur content, and MGO: marine gas oil with low sulfur content), or vessel class based on gross metric tonnage (HSD: high speed diesel $<5000$ t, MSD: medium speed diesel 5000-30000 t, or SSD: slow speed diesel $>50000 \mathrm{t}$ ); the uncertainty is computed using the orthogonal distance regression (ODR) method.

\begin{tabular}{|c|c|}
\hline Study & $\mathrm{EF}_{\mathrm{CN}}\left[\mathrm{kg}\right.$-diesel $\left.{ }^{-1}\right]$ \\
\hline This study $[d>5 \mathrm{~nm}]$ & $2.41 \pm 0.47$ (Plume 1) $0.45 \pm 0.082$ (Plume 2) $0.507 \pm 0.037$ (Plume 3 ) \\
\hline Alföldy et al. (2013) $[d>10 \mathrm{~nm}]$ & $1.05 \pm 0.10$ \\
\hline Cappa et al. (2014) $[d>3 \mathrm{~nm}]$ & $1.93(1.4 \%), 1.72(19.0 \%), 3.06(61.4 \%), 2.23(100 \%)$ \\
\hline Diesch et al. (2013) $[d>2.5 \mathrm{~nm}]$ & $3.38 \pm 3.1$ (HSD), $2.64 \pm 0.15$ (MSD), $1.96 \pm 0.70(\mathrm{SSD})$ \\
\hline Lack et al. (2009) $[d>5 \mathrm{~nm}]$ & $1.1 \pm 0.8(\mathrm{MSD}), 1.4 \pm 1.0(\mathrm{SSD})$ \\
\hline Lack et al. (2011) $[d>3-4 \mathrm{~nm}]$ & $1.0 \pm 0.2(\mathrm{MGO}), 1.4 \pm 0.2(\mathrm{HFO})$ \\
\hline Petzold et al. (2011) $[d>3-10 \mathrm{~nm}]$ & $\begin{array}{l}0.17(100 \%, \mathrm{HFO}), 0.68(75 \%, \mathrm{HFO}), 0.87(25 \%, \mathrm{HFO}), \\
0.90(10 \%, \mathrm{HFO})\end{array}$ \\
\hline Petzold et al. (2010) $[d>5 \mathrm{~nm}]$ & $\begin{array}{l}3.85 \pm 0.30(100 \%), 3.85 \pm 0.17(85 \%), 2.33 \pm 0.18(50 \%) \\
2.12 \pm 0.09(25 \%), 1.06 \pm 0.10(10 \%)\end{array}$ \\
\hline Petzold et al. (2008) $[d>3-10 \mathrm{~nm}]$ & $3.43 \pm 1.26$ \\
\hline
\end{tabular}

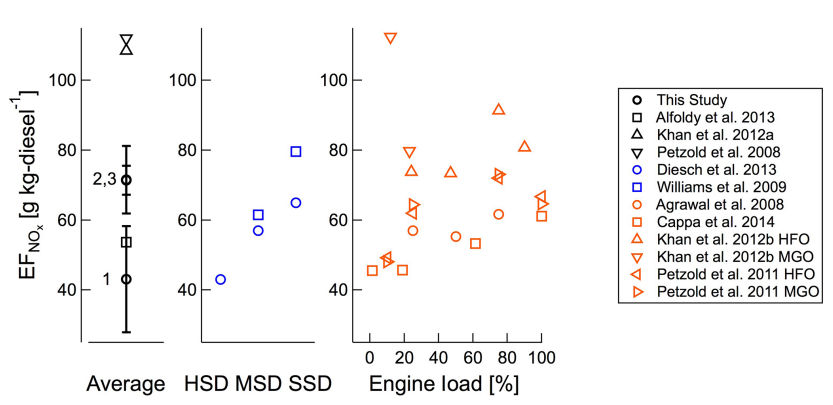

Figure 12. Emission factors for $\mathrm{NO}_{x}$; fuel type (HFO: heavy fuel oil with high sulfur content, and MGO: marine gas oil with low sulfur content), or vessel class based on gross metric tonnage (HSD: high speed diesel <5000t, MSD: medium speed diesel 500030000 t, or SSD: slow speed diesel $>50000 \mathrm{t}$ ); plumes 1,2 , and 3 are indicated on the plot with numbers 1,2 , and 3 and the estimated uncertainty is shown by error bars.

study by Petzold et al. (2011) has found decreasing $\mathrm{EF}_{\mathrm{CN}}$ with increasing engine loading.

Figure 16 and Table 7 show emission factors for cloud condensation nuclei in this study in comparison to other studies in the literature. The caveat in this comparison was the difference between supersaturation (SS) for $\mathrm{CCN}$ measurements. For this purpose SS is provided for other studies (see Table 7). $\mathrm{EF}_{\mathrm{CCN}}$ for the Amundsen was comparable to other studies at low engine load conditions and similar SS (Petzold et al., 2010; Cappa et al., 2014).

\section{Conclusions and future work}

In an effort to understand ship emissions and processing in the Arctic environment, the plume dispersion and emission factors from the Canadian Coast Guard icebreaker Amundsen were quantified near Resolute Bay, NU, Canada, during the summer 2014 NETCARE campaign. Three plumes

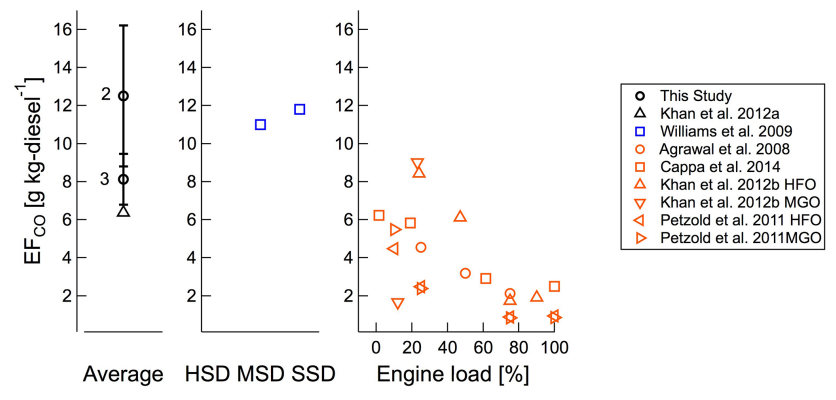

Figure 13. Emission factors for CO; fuel type (HFO: heavy fuel oil with high sulfur content, and MGO: marine gas oil with low sulfur content), or vessel class based on gross metric tonnage (HSD: high speed diesel < 5000t, MSD: medium speed diesel 5000-30000 t, or SSD: slow speed diesel $>50000 \mathrm{t}$ ); plumes 2 and 3 are indicated on the plot with numbers 2 and 3 and the estimated uncertainty is shown by error bars (plume 1 emission factor is not shown due to the large uncertainty).

$(1,2$, and 3$)$ were studied on consecutive days from 19 to 21 July 2014 by airborne interception using the Polar 6 aircraft, an analytical plume dispersion model, and by the FLEXPART-WRF dispersion model. The first plume measurement was carried out during the operation of Amundsen in the open water while moving at an average speed of $3.23 \pm 0.25 \mathrm{kts}$. The second and third plume measurements were carried out when the Amundsen reached the ice edge and operated under ice-breaking conditions with much lower speeds of $1.31 \pm 1.92$ and $0.09 \pm 0.30 \mathrm{kts}$, respectively. The engine load was low compared to cruising conditions during this campaign. The measured species included $\mathrm{CO}_{2}, \mathrm{NO}_{x}$, $\mathrm{CO}, \mathrm{SO}_{2}$, particle number concentration using a condensation particle counter (CPC), refractory black carbon (rBC), and cloud condensation nuclei (CCN). The results were compared to similar experimental studies in mid-latitudes. 
Table 7. Emission factors for cloud condensation nuclei $\times 10^{14}$; numbers in brackets indicate engine load (\%), fuel type (HFO: heavy fuel oil with high sulfur content, and MGO: marine gas oil with low sulfur content), or vessel class based on gross metric tonnage (HSD: high speed diesel < 5000 t, MSD: medium speed diesel 5000-30000 t, or SSD: slow speed diesel > 50 $000 \mathrm{t}$ ); the uncertainty is computed using the orthogonal distance regression (ODR) method.

\begin{tabular}{ll}
\hline Study & $\mathrm{EF}_{\mathrm{CCN}}\left[\mathrm{kg}_{\text {-diesel }}{ }^{-1}\right]$ \\
\hline This study $[\mathrm{SS}=0.6 \%]$ & $3.03 \pm 0.933$ (Plume 1) $1.39 \pm 0.319$ (Plume 2) $0.650 \pm 0.136$ (Plume 3) \\
Cappa et al. (2014) [SS=0.6\%] & $0.83(1.4 \%), 0.7(19.0 \%), 0.63(100 \%)$ \\
Lack et al. (2009) [SS $=0.44 \%]$ & $5.0 \pm 3.0(\mathrm{MSD}), 24 \pm 20(\mathrm{SSD})$ \\
Lack et al. (2011) [SS $=0.3 \%]$ & $40 \pm 4(\mathrm{MGO}), 1.0 \pm 0.1(\mathrm{HFO})$ \\
Petzold et al. (2010) $[\mathrm{SS}=0.3 \%]$ & $1.08(100 \%), 0.37(85 \%), 0.80(50 \%), 1.58(25 \%), 6.15(10 \%)$ \\
\hline
\end{tabular}

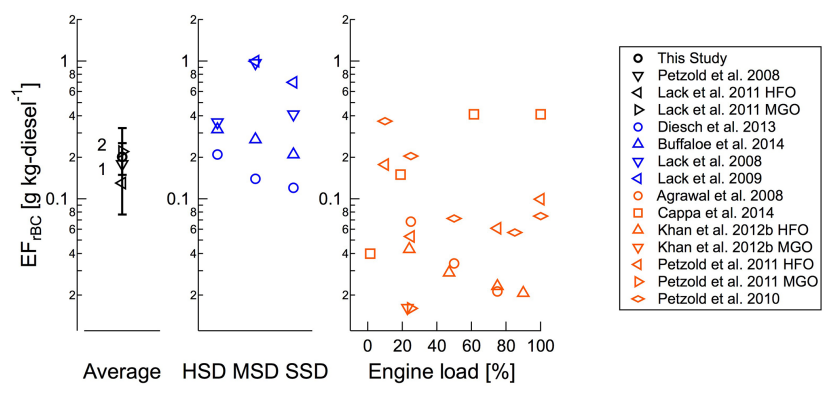

Figure 14. Emission factors for black carbon; fuel type (HFO: heavy fuel oil with high sulfur content, and MGO: marine gas oil with low sulfur content), or vessel class based on gross metric tonnage (HSD: high speed diesel $<5000 \mathrm{t}$, MSD: medium speed diesel 5000-30000 t, or SSD: slow speed diesel $>50000 \mathrm{t}$ ); plumes 1 and 2 are indicated on the plot with numbers 1 and 2 and the estimated uncertainty is shown by error bars (plume 3 emission factor is not shown because the instrument was malfunctioning during this experiment).

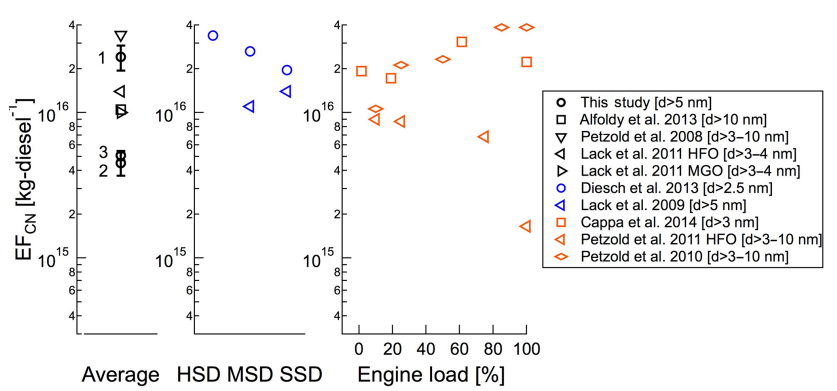

Figure 15. Emission factors for total particle count; fuel type (HFO: heavy fuel oil with high sulfur content, and MGO: marine gas oil with low sulfur content), or vessel class based on gross metric tonnage (HSD: high speed diesel $<5000 \mathrm{t}, \mathrm{MSD}$ : medium speed diesel 5000-30000 t, or SSD: slow speed diesel > 50000 t); plumes 1, 2, and 3 are indicated on the plot with numbers 1,2, and 3 and the estimated uncertainty is shown by error bars.

The calculated analytical expansion rates were $\gamma=0.75 \pm$ $0.81,0.93 \pm 0.37$, and $1.19 \pm 0.39$ for plumes 1,2 , and 3 , respectively. These were lower than observations in mid-

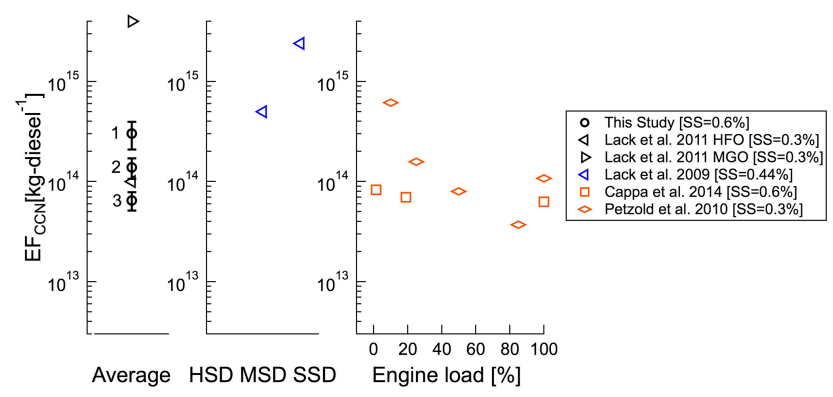

Figure 16. Emission factors for cloud condensation nuclei; fuel type (HFO: heavy fuel oil with high sulfur content, and MGO: marine gas oil with low sulfur content), or vessel class based on gross metric tonnage (HSD: high speed diesel < 5000t, MSD: medium speed diesel 5000-30000 t, or SSD: slow speed diesel $>50000 \mathrm{t}$ ); plumes 1,2 , and 3 are indicated on the plot with numbers 1,2 , and 3 and the estimated uncertainty is shown by error bars.

latitudes. All emission factors were in agreement with other observations at low engine loads in mid-latitudes. Icebreaking appeared to increase the $\mathrm{NO}_{x}$ emission factor from $\mathrm{EF}_{\mathrm{NO}_{x}}=43.1 \pm 15.2$ to $71.6 \pm 9.68$ and $71.4 \pm 4.14 \mathrm{~g} \mathrm{~kg}-$ diesel $^{-1}$ for plumes 1,2 , and 3, possibly due to high engine temperatures. The $\mathrm{CO}$ emission factor was $\mathrm{EF}_{\mathrm{CO}}=137 \pm$

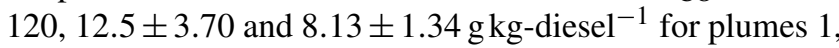
2 , and 3. The $\mathrm{rBC}$ emission factor was $\mathrm{EF}_{\mathrm{rBC}}=0.202 \pm 0.052$ and $0.202 \pm 0.125 \mathrm{~g} \mathrm{~kg}$-diesel ${ }^{-1}$ for plumes 1 and 2 . The $\mathrm{CN}$ emission factor was reduced while ice-breaking from $\mathrm{EF}_{\mathrm{CN}}=2.41 \pm 0.47$ to $0.45 \pm 0.082$ and $0.507 \pm 0.037 \times$ $10^{16} \mathrm{~kg}^{- \text {diesel }^{-1}}$ for plumes 1,2 , and 3 . At $0.6 \%$ supersaturation, the $\mathrm{CCN}$ emission factor was similar to observations in mid-latitudes at low engine loads with $\mathrm{EF}_{\mathrm{CCN}}=3.03 \pm$ $0.933,1.39 \pm 0.319$ and $0.650 \pm 0.136 \times 10^{14} \mathrm{~kg}$-diesel $^{-1}$ for plumes 1,2 , and 3 .

The difference in plume expansion rate compared to midlatitude observations was attributed to unique physics of the Arctic boundary layer, which was characterized by reduced turbulent mixing due to the thermally stable boundary layer. In addition, ship operation at partial engine load and icebreaking mode contributed to different emission factors compared to cruising conditions. 
One limitation of this study was that the Amundsen plume was not intercepted at higher engine loads near cruising conditions. Future studies should measure the emission factors and plume geometrical evolution under such conditions to provide a more complete understanding of plume chemistry and physics over the Arctic marine boundary layer.

\section{Data availability}

Experimental data: NETCARE, which organized the aircraft flight campaign described in this paper, is moving towards a publicly available, online data archive. In the meantime, the data can be accessed by emailing the principal investigator of the network: Jon Abbatt at the University of Toronto (jabbatt@chem.utoronto.ca) Numerical data: The WRF modeling system can be downloaded from NCAR (http://www2. mmm.ucar.edu/wrf/users/download/get_source.html; WRF, 2016). The FLEXPART-WRF model is also freely available for use from FLEXPART.eu (https://www.flexpart.eu/wiki/ FpLimitedareaWrf; FLEXPART, 2016).

Acknowledgements. The authors acknowledge a large number of people for their contributions to this work. We appreciate expert internal review of the manuscript by Pacal Bellavance and Paul Izdebski (Environment and Climate Change Canada - ECCC). We thank Tim Papakyriakou and Greg Wentworth for providing ship track and speed information. We thank Kenn Borek Air, in particular Kevin Elkes and John Bayes for their skillful piloting that facilitated these plume observations. We are grateful to John Ford and the University of Toronto (UofT) machine shop, Jim Hodgson and Lake Central Air Services in Muskoka, Jim Watson (Scale Modelbuilders, Inc.), Julia Binder and Martin Gehrman (Alfred Wegener Institute - AWI - Helmholtz Center for Polar and Marine Research), Mike Harwood and Andrew Elford (ECCC), for their support of the integration of the instrumentation and aircraft, Yuan You (ECCC), for helping with data analysis, and Jeremy Wentzell (ECCC), for sharing an $\mathrm{SO}_{2}$ mixing ratio dataset that was collected on-board of the Amundsen. We thank Mohammed Wasey for his expert support of the instrumentation during the integration and in the field. French authors acknowledge funding support from the European Union ACCESS (Arctic Climate Change, Economy and Society) project under Grant Agreement No. 5265863 and TOTAL SA via an ANRT Cifre $\mathrm{PhD}$ grant. Computer simulations were performed on the IPSL mesoscale computer center (Mésocentre IPSL), which includes support for calculations and data storage facilities. The authors want to thank the ship commander, Alain Lacerte, and the crew of the Amundsen for their support. We are grateful to Stewart Cober and Carrie Taylor (ECCC), Bob Christensen (UofT), Kevin Riehl (Kenn Borek Air), Lukas Kandora and Jens Herrmann (AWI), Desiree Toom, Sangeeta Sharma, Dan Veber, Andrew Platt, Anne Marie Macdonald, and Maurice Watt (ECCC) for their support of the study. We thank the Biogeochemistry department of Max-Planck-Institut für Chemie (MPIC) for providing the $\mathrm{CO}$ instrument and Dieter Scharffe for his excellent support during the preparation phase of the campaign. We thank the Nunavut Research Institute and the Nunavut Impact Review
Board for licensing the study. Logistical support in Resolute Bay was provided by the Polar Continental Shelf Project (PCSP) of Natural Resources Canada for Field Project \#218-14, and we are particularly grateful to Tim McCagherty and Jodi MacGregor of the PCSP. Funding for this work was provided by the Natural Sciences and Engineering Research Council of Canada (NSERC) under the CCAR NETCARE project, the Alfred Wegener Institute (AWI), and Environment and Climate Change Canada (ECCC). The authors are indebted to Harald Saathoff for editing and Viola Hennecke for careful typesetting of this manuscript, which involved overwhelming level details.

Edited by: H. Saathoff

\section{References}

Agrawal, H., Welch, W. A., Miller, J. W., and Cocker, D. R.: Emission measurements from a crude oil tanker at sea, Environ. Sci. Technol., 42, 7098-7103, doi:10.1021/es703102y, 2008.

Agrawal, H., Welch, W. A., Henningsen, S., Miller, J. W., and Cocker, D. R.: Emissions from main propulsion engine on container ship at sea, J. Geophys. Res.-Atmos., 115, d23205, doi:10.1029/2009JD013346, 2010.

Alföldy, B., Lööv, J. B., Lagler, F., Mellqvist, J., Berg, N., Beecken, J., Weststrate, H., Duyzer, J., Bencs, L., Horemans, B., Cavalli, F., Putaud, J.-P., Janssens-Maenhout, G., Csordás, A. P., Van Grieken, R., Borowiak, A., and Hjorth, J.: Measurements of air pollution emission factors for marine transportation in SECA, Atmos. Meas. Tech., 6, 1777-1791, doi:10.5194/amt-61777-2013, 2013.

Aliabadi, A. A., Staebler, R. M., and Sharma, S.: Air quality monitoring in communities of the Canadian Arctic during the high shipping season with a focus on local and marine pollution, Atmos. Chem. Phys., 15, 2651-2673, doi:10.5194/acp-15-26512015, 2015.

Aliabadi, A. A., Staebler, R. M., de Grandpré, J., Zadra, A., and Vaillancourt, P. A.: Comparison of estimated atmospheric boundary layer mixing height in the Arctic and southern Great Plains under statically stable conditions: experimental and numerical aspects, Atmos. Ocean., 54, 60-74, doi:10.1080/07055900.2015.1119100, 2016a.

Aliabadi, A. A., Staebler, R. M., Liu, M., and Herber, A.: Characterization and parametrization of Reynolds stress and turbulent heat flux in the stably-stratified lower Arctic troposphere using aircraft measurements, Bound.-Lay. Meteorol., doi:10.1007/s10546-016-0164-7, online first, 2016b.

Anderson, P. S. and Neff, W. D.: Boundary layer physics over snow and ice, Atmos. Chem. Phys., 8, 3563-3582, doi:10.5194/acp-83563-2008, 2008.

Balzani Lööv, J. M., Alfoldy, B., Gast, L. F. L., Hjorth, J., Lagler, F., Mellqvist, J., Beecken, J., Berg, N., Duyzer, J., Westrate, H., Swart, D. P. J., Berkhout, A. J. C., Jalkanen, J.-P., Prata, A. J., van der Hoff, G. R., and Borowiak, A.: Field test of available methods to measure remotely $\mathrm{SO}_{x}$ and $\mathrm{NO}_{x}$ emissions from ships, Atmos. Meas. Tech., 7, 2597-2613, doi:10.5194/amt-7-2597-2014, 2014.

Beecken, J., Mellqvist, J., Salo, K., Ekholm, J., Jalkanen, J.-P., Johansson, L., Litvinenko, V., Volodin, K., and Frank-Kamenetsky, D. A.: Emission factors of $\mathrm{SO}_{2}, \mathrm{NO}_{x}$ and particles from ships 
in Neva Bay from ground-based and helicopter-borne measurements and AIS-based modeling, Atmos. Chem. Phys., 15, 52295241, doi:10.5194/acp-15-5229-2015, 2015.

Berg, N., Mellqvist, J., Jalkanen, J.-P., and Balzani, J.: Ship emissions of $\mathrm{SO}_{2}$ and $\mathrm{NO}_{2}$ : DOAS measurements from airborne platforms, Atmos. Meas. Tech., 5, 1085-1098, doi:10.5194/amt-51085-2012, 2012.

Boggs, P. T., Byrd, R. H., and Schnabel, R. B.: A Stable and efficient algorithm for nonlinear orthogonal distance regression, SIAM J. Sci. Stat. Comput., 8, 1052-1078, doi:10.1137/0908085, 1987.

Boggs, P. T., Spiegelman, C. H., Donaldson, J. R., and Schnabel, R. B.: A computational examination of orthogonal distance regression, J. Econometrics, 38, 169-201, doi:10.1016/03044076(88)90032-2, 1988.

Boggs, P. T., Donaldson, J. R., Byrd, R. H., and Schnabel, R. B.: Algorithm 676: ODRPACK: software for weighted orthogonal distance regression, ACM T. Math. Software, 15, 348-364, doi:10.1145/76909.76913, 1989.

Brioude, J., Arnold, D., Stohl, A., Cassiani, M., Morton, D., Seibert, P., Angevine, W., Evan, S., Dingwell, A., Fast, J. D., Easter, R. C., Pisso, I., Burkhart, J., and Wotawa, G.: The Lagrangian particle dispersion model FLEXPART-WRF version 3.1, Geosci. Model Dev., 6, 1889-1904, doi:10.5194/gmd-61889-2013, 2013.

Buffaloe, G. M., Lack, D. A., Williams, E. J., Coffman, D., Hayden, K. L., Lerner, B. M., Li, S.-M., Nuaaman, I., Massoli, P., Onasch, T. B., Quinn, P. K., and Cappa, C. D.: Black carbon emissions from in-use ships: a California regional assessment, Atmos. Chem. Phys., 14, 1881-1896, doi:10.5194/acp-14-18812014, 2014.

Cai, Y., Montague, D. C., Mooiweer-Bryan, W., and Deshler, T.: Performance characteristics of the ultra high sensitivity aerosol spectrometer for particles between 55 and $800 \mathrm{~nm}$ : laboratory and field studies, J. Aerosol Sci., 39, 759-769, doi:10.1016/j.jaerosci.2008.04.007, 2008.

Cappa, C. D., Williams, E. J., Lack, D. A., Buffaloe, G. M., Coffman, D., Hayden, K. L., Herndon, S. C., Lerner, B. M., Li, S.M., Massoli, P., McLaren, R., Nuaaman, I., Onasch, T. B., and Quinn, P. K.: A case study into the measurement of ship emissions from plume intercepts of the NOAA ship Miller Freeman, Atmos. Chem. Phys., 14, 1337-1352, doi:10.5194/acp-14-13372014, 2014.

Chen, G., Huey, L. G., Trainer, M., Nicks, D., Corbett, J., Ryerson, T., Parrish, D., Neuman, J. A., Nowak, J., Tanner, D., Holloway, J., Brock, C., Crawford, J., Olson, J. R., Sullivan, A., Weber, R., Schauffler, S., Donnelly, S., Atlas, E., Roberts, J., Flocke, F., Hübler, G., and Fehsenfeld, F.: An investigation of the chemistry of ship emission plumes during ITCT 2002, J. Geophys. Res.Atmos., 110, D10S90, doi:10.1029/2004JD005236, 2005.

Cooper, D.: HCB, PCB, PCDD and PCDF emissions from ships, Atmos. Environ., 39, 4901-4912, doi:10.1016/j.atmosenv.2005.04.037, 2005.

Corbett, J. J., Lack, D. A., Winebrake, J. J., Harder, S., Silberman, J. A., and Gold, M.: Arctic shipping emissions inventories and future scenarios, Atmos. Chem. Phys., 10, 9689-9704, doi:10.5194/acp-10-9689-2010, 2010a.

Corbett, J. J., Winebrake, J. J., and Green, E. H.: An assessment of technologies for reducing regional short-lived climate forcers emitted by ships with implications for Arctic shipping, Future Sci., 1, 207-225, doi:10.4155/cmt.10.27, 2010 b.

Diesch, J.-M., Drewnick, F., Klimach, T., and Borrmann, S.: Investigation of gaseous and particulate emissions from various marine vessel types measured on the banks of the Elbe in Northern Germany, Atmos. Chem. Phys., 13, 3603-3618, doi:10.5194/acp-133603-2013, 2013.

Eckhardt, S., Hermansen, O., Grythe, H., Fiebig, M., Stebel, K., Cassiani, M., Baecklund, A., and Stohl, A.: The influence of cruise ship emissions on air pollution in Svalbard - a harbinger of a more polluted Arctic?, Atmos. Chem. Phys., 13, 8401-8409, doi:10.5194/acp-13-8401-2013, 2013.

FLEXPART: FLEXPART - WRF versions, available at: https://www.flexpart.eu/wiki/FpLimitedareaWrf, last access: 23 June 2016.

Hobbs, P. V., Garrett, T. J., Ferek, R. J., Strader, S. R., Hegg, D. A., Frick, G. M., Hoppel, W. A., Gasparovic, R. F., Russell, L. M., Johnson, D. W., O'Dowd, C., Durkee, P. A., Nielsen, K. E., and Innis, G.: Emissions from ships with respect to their effects on clouds, J. Atmos. Sci., 57, 2570-2590, doi:10.1175/15200469(2000)057<2570:EFSWRT>2.0.CO;2, 2000.

IMO: Pollution Prevention, available at: http://www.imo.org/en/ OurWork/Environment/PollutionPrevention/Pages/Default.aspx, last access: 9 December 2015.

Jalkanen, J.-P., Johansson, L., Kukkonen, J., Brink, A., Kalli, J., and Stipa, T.: Extension of an assessment model of ship traffic exhaust emissions for particulate matter and carbon monoxide, Atmos. Chem. Phys., 12, 2641-2659, doi:10.5194/acp-12-26412012, 2012.

Khan, M. Y., Agrawal, H., Ranganathan, S., Welch, W. A., Miller, J. W., and Cocker, D. R.: Greenhouse gas and criteria emission benefits through reduction of vessel speed at sea, Environ. Sci. Technol., 46, 12600-12607, doi:10.1021/es302371f, 2012a.

Khan, M. Y., Giordano, M., Gutierrez, J., Welch, W. A., AsaAwuku, A., Miller, J. W., and Cocker, D. R.: Benefits of two mitigation strategies for container vessels: cleaner engines and cleaner fuels, Environ. Sci. Technol., 46, 5049-5056, doi:10.1021/es2043646, 2012b.

Kivekäs, N., Massling, A., Grythe, H., Lange, R., Rusnak, V., Carreno, S., Skov, H., Swietlicki, E., Nguyen, Q. T., Glasius, M., and Kristensson, A.: Contribution of ship traffic to aerosol particle concentrations downwind of a major shipping lane, Atmos. Chem. Phys., 14, 8255-8267, doi:10.5194/acp-14-8255-2014, 2014.

Lack, D., Lerner, B., Granier, C., Baynard, T., Lovejoy, E., Massoli, P., Ravishankara, A. R., and Williams, E.: Light absorbing carbon emissions from commercial shipping, Geophys. Res. Lett., 35, L13815, doi:10.1029/2008GL033906, 2008.

Lack, D. A. and Corbett, J. J.: Black carbon from ships: a review of the effects of ship speed, fuel quality and exhaust gas scrubbing, Atmos. Chem. Phys., 12, 3985-4000, doi:10.5194/acp-12-39852012, 2012.

Lack, D. A., Corbett, J. J., Onasch, T. B., Lerner, B., Massoli, P., Quinn, P. K., Bates, T. S., Covert, D. S., Coffman, D., Sierau, B., Herndon, S., Allan, J., Baynard, T., Lovejoy, E., Ravishankara, A. R., and Williams, E.: Particulate emissions from commercial shipping: chemical, physical, and optical properties, J. Geophys. Res.-Atmos., 114, doi:10.1029/2008JD011300, d00F04, 2009. 
Lack, D. A., Cappa, C. D., Langridge, J., Bahreini, R., Buffaloe, G., Brock, C., Cerully, K., Coffman, D., Hayden, K., Holloway, J., Lerner, B., Massoli, P., Li, S.-M., McLaren, R., Middlebrook, A. M., Moore, R., Nenes, A., Nuaaman, I., Onasch, T. B., Peischl, J., Perring, A., Quinn, P. K., Ryerson, T., Schwartz, J. P., Spackman, R., Wofsy, S. C., Worsnop, D., Xiang, B., and Williams, E.: Impact of fuel quality regulation and speed reductions on shipping emissions: implications for climate and air quality, Environ. Sci. Technol., 45, 9052-9060, doi:10.1021/es2013424, 2011.

Leaitch, W. R., Korolev, A., Aliabadi, A. A., Burkart, J., Willis, M., Abbatt, J. P. D., Bozem, H., Hoor, P., Köllner, F., Schneider, J., Herber, A., Konrad, C., and Brauner, R.: Effects of 20-100 nanometre particles on liquid clouds in the clean summertime Arctic, Atmos. Chem. Phys. Discuss., doi:10.5194/acp-2015999, in review, 2016.

Mahrt, L.: Modelling the depth of the stable boundary-layer, Bound.-Lay. Meteorol., 21, 3-19, doi:10.1007/BF00119363, 1981.

Marelle, L., Thomas, J. L., Raut, J.-C., Law, K. S., Jalkanen, J.P., Johansson, L., Roiger, A., Schlager, H., Kim, J., Reiter, A., and Weinzierl, B.: Air quality and radiative impacts of Arctic shipping emissions in the summertime in northern Norway: from the local to the regional scale, Atmos. Chem. Phys., 16, 23592379, doi:10.5194/acp-16-2359-2016, 2016.

McLaren, R., Wojtal, P., Halla, J. D., Mihele, C., and Brook, J. R.: A survey of $\mathrm{NO}_{2}: \mathrm{SO}_{2}$ emission ratios measured in marine vessel plumes in the strait of Georgia, Atmos. Environ., 46, 655-658, doi:10.1016/j.atmosenv.2011.10.044, 2012.

Miola, A., Ciuffo, B., Giovine, E., and Marra, M.: Regulating air emissions from ships: the state of the art on methodologies, technologies and policy options, Report, European Commission Joint Research Centre - Institute for Environment and Sustainability (ISBN 978-92-79-17733-0), JRC-IES, Via Enrico Fermi, 2749-21027 - Ispra (VA) - Italy, doi:10.2788/4171, 2010.

Moldanová, J., Fridell, E., Popovicheva, O., Demirdjian, B., Tishkova, V., Faccinetto, A., and Focsa, C.: Characterisation of particulate matter and gaseous emissions from a large ship diesel engine, Atmos. Environ., 43, 2632-2641, doi:10.1016/j.atmosenv.2009.02.008, 2009.

Petzold, A., Hasselbach, J., Lauer, P., Baumann, R., Franke, K., Gurk, C., Schlager, H., and Weingartner, E.: Experimental studies on particle emissions from cruising ship, their characteristic properties, transformation and atmospheric lifetime in the marine boundary layer, Atmos. Chem. Phys., 8, 2387-2403, doi:10.5194/acp-8-2387-2008, 2008.

Petzold, A., Weingartner, E., Hasselbach, J., Lauer, P., Kurok, C., and Fleischer, F.: Physical properties, chemical composition, and cloud forming potential for particulate emissions from a marine diesel engine at various load conditions, Environ. Sci. Technol., 44, 3800-3805, doi:10.1021/es903681z, 2010.

Petzold, A., Lauer, P., Fritsche, U., Hasselbach, J., Lichtenstern, M., Schlager, H., and Fleischer, F.: Operation of marine diesel engines on biogenic fuels: modification of emissions and resulting climate effects, Environ. Sci. Technol., 45, 10394-10400, doi:10.1021/es2021439, 2011.

Pirjola, L., Pajunoja, A., Walden, J., Jalkanen, J.-P., Rönkkö, T., Kousa, A., and Koskentalo, T.: Mobile measurements of ship emissions in two harbour areas in Finland, Atmos. Meas. Tech., 7, 149-161, doi:10.5194/amt-7-149-2014, 2014.

Pizzolato, L., Howell, S. E. L., Derksen, C., Dawson, J., and Copland, L.: Changing sea ice conditions and marine transportation activity in Canadian Arctic waters between 1990 and 2012, Climatic Change, 123, 161-173, doi:10.1007/s10584-013-1038-3, 2014.

Roiger, A., Thomas, J.-L., Schlager, H., Law, K. S., Kim, J., Schäfler, A., Weinzierl, B., Dahlkötter, F., Krisch, I., Marelle, L., Minikin, A., Raut, J.-C., Reiter, A., Rose, M., Scheibe, M., Stock, P., Baumann, R., Bouarar, I., Clerbaux, C., George, M., Onishi, T., and Flemming, J.: Quantifying emerging local anthropogenic emissions in the Arctic region: the ACCESS aircraft campaign experiment, B. Am. Meteorol. Soc., 96, 441-460, doi:10.1175/BAMS-D-13-00169.1, 2015.

Schwarz, J. P., Spackman, J. R., Gao, R. S., Perring, A. E., Cross, E., Onasch, T. B., Ahern, A., Wrobel, W., Davidovits, P., Olfert, J., Dubey, M. K., Mazzoleni, C., and Fahey, D. W.: The detection efficiency of the single particle soot photometer, Aerosol Sci. Tech., 44, 612-628, doi:10.1080/02786826.2010.481298, 2010.

Sinha, P., Hobbs, P. V., Yokelson, R. J., Christian, T. J., Kirchstetter, T. W., and Bruintjes, R.: Emissions of trace gases and particles from two ships in the southern Atlantic ocean, Atmos. Environ., 37, 2139-2148, doi:10.1016/S1352-2310(03)00080-3, 2003.

Skamarock, W. C., Klemp, J. B., Dudhia, J., Gill, D. O., Barker, D. M., Wang, W., and Powers, J. G.: A description of the advanced research WRF version 2, Tech. rep., National Center for Atmos. Res., Technical Note, Boulder, Colorado, USA, available at: www2.mmm.ucar.edu/wrf/users/docs/arw_v2_070111. pdf (last access: 9 December 2015), 2005.

Stohl, A., Forster, C., Frank, A., Seibert, P., and Wotawa, G.: Technical note: The Lagrangian particle dispersion model FLEXPART version 6.2, Atmos. Chem. Phys., 5, 2461-2474, doi:10.5194/acp-5-2461-2005, 2005.

von Glasow, R., Lawrence, M. G., Sander, R., and Crutzen, P. J.: Modeling the chemical effects of ship exhaust in the cloudfree marine boundary layer, Atmos. Chem. Phys., 3, 233-250, doi:10.5194/acp-3-233-2003, 2003.

Wentworth, G. R., Murphy, J. G., Croft, B., Martin, R. V., Pierce, J. R., Côté, J.-S., Courchesne, I., Tremblay, J.-É., Gagnon, J., Thomas, J. L., Sharma, S., Toom-Sauntry, D., Chivulescu, A., Levasseur, M., and Abbatt, J. P. D.: Ammonia in the summertime Arctic marine boundary layer: sources, sinks, and implications, Atmos. Chem. Phys., 16, 1937-1953, doi:10.5194/acp-16-19372016, 2016.

Williams, E. J., Lerner, B. M., Murphy, P. C., Herndon, S. C., and Zahniser, M. S.: Emissions of $\mathrm{NO}_{X}, \mathrm{SO}_{2}, \mathrm{CO}$, and $\mathrm{HCHO}$ from commercial marine shipping during Texas Air Quality Study (TexAQS) 2006, J. Geophys. Res.-Atmos., 114, D21306, doi:10.1029/2009JD012094, 2009.

Winther, M., Christensen, J. H., Plejdrup, M. S., Ravn, E. S., Eriksson, O. F., and Kristensen, H. O.: Emission inventories for ships in the arctic based on satellite sampled AIS data, Atmos. Environ., 91, 1-14, doi:10.1016/j.atmosenv.2014.03.006, 2014.

WRF: WRF Source Codes and Graphics Software Downloads, available at: http://www2.mmm.ucar.edu/wrf/users/download/ get_source.html, last access: 23 June 2016. 